\title{
Laboratorio confinado. Arquitectura moderna en el norte de Chile
}

\author{
Confined laboratory. Modern architecture in northern Chile
}

<Resumen>

La arquitectura moderna proyectada para el norte de Chile, fue el producto de iniciativas de diversas instituciones nacionales y regionales. La receptividad de las jóvenes y cosmopolitas sociedades permitió que diversos arquitectos desarrollaran edificios especialmente para el norte, primero con un racionalismo ortodoxo, pero luego explorando resoluciones que integraron el clima y la topografía del desierto, creando un singular laboratorio de modernidad.

$<$ Abstract $>$

Modern architecture planned for northern chile, was the product of efforts of various national and regional institutions The responsiveness of the young and cosmopolitan societies allowed several architects to develop buildings especially for the north, first with an orthodox rationalism, but then exploring resolutions that integrated the climate and topography of the desert, creating a unique laboratory for modernity.

<PALABRAS CLAVE>

ARQUITECTURA MODERNA / NORTE DE CHILE / REGIONALISMO / ZONAS ÁRIDAS / SIGLO XX

\section{<KEYWORDS>}

MODERN ARCHITECTURE / NORTHERN CHILE \& REGIONALISM \& ARID ZONES \& TWENTIETH CENTURY
Investigar el legado de la modernidad en el norte de Chile, significa acudir a una producción arquitectónica confinada durante la posmodernidad ${ }^{1}$

El proceso de generación del proyecto moderno para el norte chileno fue una prolongación de la producción arquitectónica nacional estimulado, en muchos casos, por políticas de instituciones del Estado. En general se acude a la condición de lejanía de nuestro país para justificar acciones y resultados experimentales de nuestra resguardada escena cultural. Pero para el norte no necesariamente hubo una mayor distancia, ya que estuvo muy conectado, primero con el ferrocarril y tráfico marítimo y luego con el moderno desarrollo de la aviación comercial, siendo, principalmente Antofagasta, parada obligada o destino en las rutas hacia el norte o sur del continente, entre Lima (proveniente o dirigido a Estados Unidos), hacia o desde Santiago y Buenos Aires². El distanciamiento más bien se podría entender por la inexistencia de

* Claudio Galeno Ibaceta, arquitecto graduado en la Universidad Católica del Norte (1997). Master Historia, Arte, Arquitectura y Ciudad, ETSAB-UPC (2001), y candidato a Doctor en Teoría e Historia de la Arquitectura ETSABUPC. Profesor titular del Departamento de Arquitectura de la UCN. Miembro de Docomomo-Chile y organizador de su Segundo Seminario Nacional. Director revista Cuadernos de Arquitectura. Desde el 2002 realiza investigaciones sobre la modernidad en el norte de Chile, con temas como: salud (2003-2004), colectivos obreros (2004-2005), campus universitarios (2005-2006) y turismo (2006-2007). Ha expuesto sus investigaciones en los Seminarios de Arquitectura Latinoamericana, y en los Seminarios de Docomomo-Chile. Tiene publicaciones en revistas internacionales y nacionales. Colabora continuamente con la escena artística contemporánea de Antofagasta, en aspectos teóricos e históricos y en videoarte.

El proceso de confinamiento, que no ocurre sólo en el norte, se debe a la anulación de la memoria cultura impuesta por la dictadura, con la consecuente amnesia colectiva, olvidando la estima y credibilidad social que existió en la modernidad como signo de bienestar y progreso.

2 Claudio Galeno I. Destinos y pertenencia: arquitecturas para el turismo moderno en el norte de Chile. En: Resumenes de Ponencias, SAL XII, Seminario de Arquitectura Latinoamericana, Pensamiento construido. La investigación en arquitectura y urbanismo en Latinoamérica, Concepción: Facultad de Arquitectura, Construcción y Diseño, Universidad del Bío-Bío, 10-17 de noviembre de 2007; p. 104 
instituciones universitarias que desarrollaran la enseñanza de la arquitectura ${ }^{3}$, a pesar de que si hubo para las artes desde los años 50 . De cualquier forma eso no impidió que muchos arquitectos actuaran en la conformación de un laboratorio donde se desarrollaron propuestas en una variedad de ambientes desérticos dirigido hacia sociedades receptivas de la nueva arquitectura y de la renovación que la acompañaba. Siendo el resultado de estas diversas producciones, espacios urbanos de identidad moderna que poseen obras que potencian su singularidad al reconocer los lugares donde se insertan.

En el norte los lugares donde se produjeron la mayor concentración de obras modernas fueron ciudades puerto y ciudades industriales vinculadas a la minería. En algunas la modernidad fue crucial, siendo uno de los momentos más relevantes en la producción de una imagen de ciudad racional. En esa situación privilegiada podemos mencionar Arica y Antofagasta. Pero en otras podríamos destacar la existencia de obras específicas o sectores de mucho valor que merecen un amplio estudio, como en los casos de Iquique, Tocopilla, Calama, Chañaral, Copiapó 4 , Vallenar ${ }^{5}$ y Ovalle. Otros sitios que destacarían por representar una modernidad en transición, en muchos casos por su innovadora organización urbana de ciudad industrial, serían asentamientos mineros como Maria Elena, Pedro de Valdivia, Chacabuco y Chuquicamata, mientras que en los casos de El Salvador, proyectado por el Departamento de ingeniería de la Anaconda Cooper Mining Co., y la Fundición Nacional de Paipote, 19471952, diseñada por el arquitecto Svetozar Goic $^{6}$ poseen resoluciones definitivamente modernas.

Entre las principales instituciones que definen un arribo de la modernidad, o un principio de ese campo de pruebas, está la Caja de Seguro Obrero, con los Edificios Colectivos, ya que así como representan una iniciativa sin

Recién en 1982 fue creada, en la Universidad del Norte de Antofagasta, la carrera de arquitectura, por la arquitecta Ángela Schweitzer Lopetegui. En Copiapó habría que investigar la obra para el Servicio de Seguro Social de Jorge Aguirre Silva, 1960, el Grupo Escolar (demolido), de 1940. En Vallenar existe una peculiar construcción finalizada tardíamente, el Edificio de la CAP en Vallenar, actual sede de la CMP, proyectado por Víctor Gubbins y Christian de Groote; también se podrían mencionar la Compañía de Bomberos y el antiguo Aeródromo de LAN Chile.

Arquitecto titulado en la Universidad de Chile, que ejerció durante varios años de forma privada en Copiapó

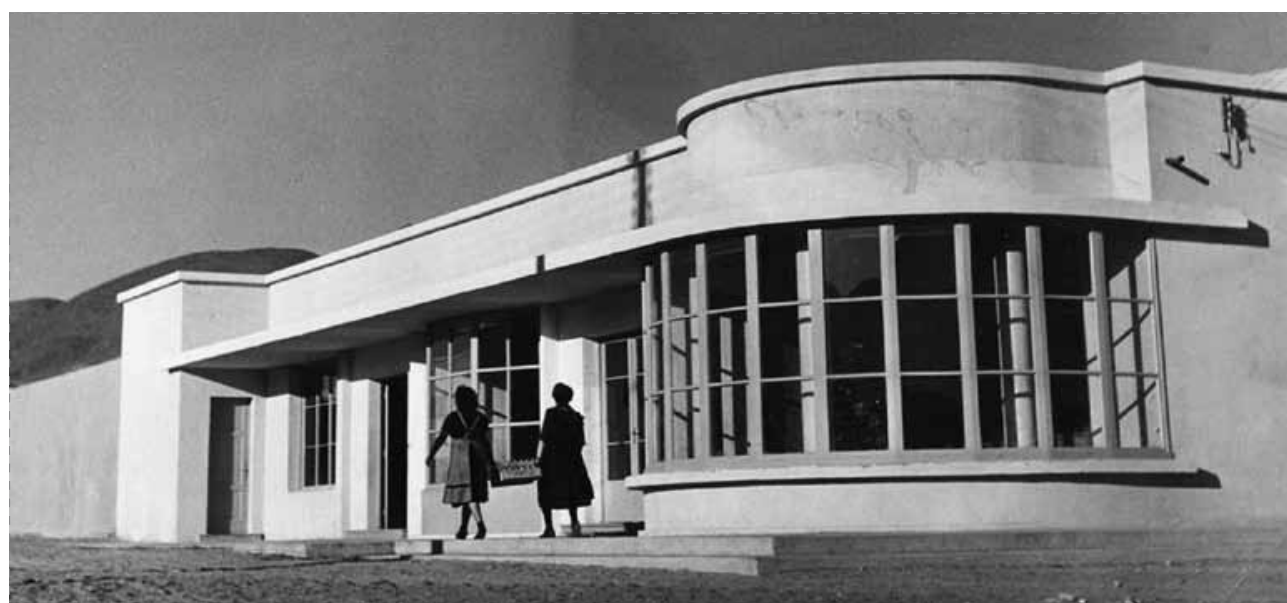

Pulpería, Paipote, 1950, arquitecto Svetozar Goic. @ Foto Danilo Goic, en Cancino, Juan Carlos, FUNDICIÓN PAIPOTE 1952. Territorio. Asentamiento y Arquitectura en el Período de la Industrialización Nacional. Tesis de Magíster en Arquitectura Tutor: Eugenio Garcés Feliu, Santiago de Chile, PUC, 2008

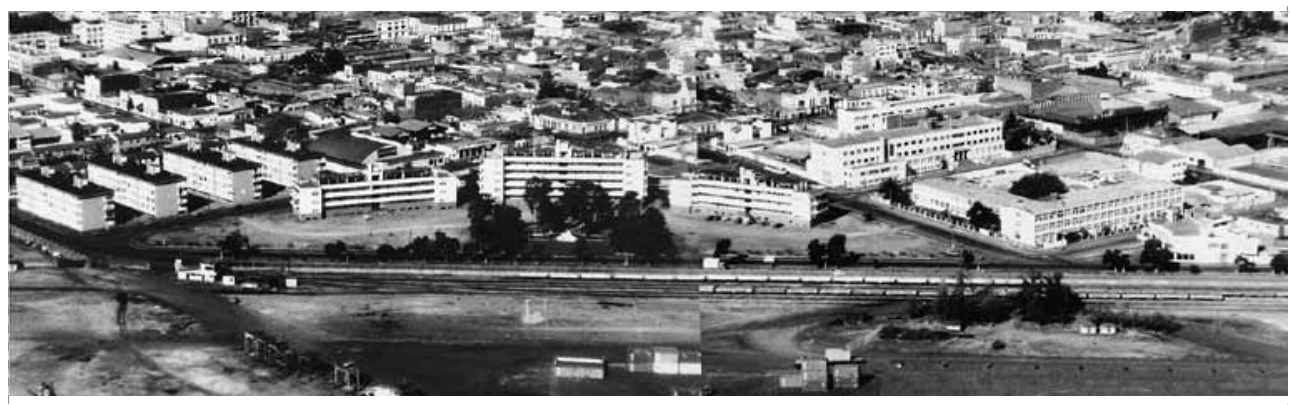

Colectivos Obreros en Antofagasta, Caja de Seguro Obrero Obligatorio, 1939-1942. (c) Archivo Claudio Galeno

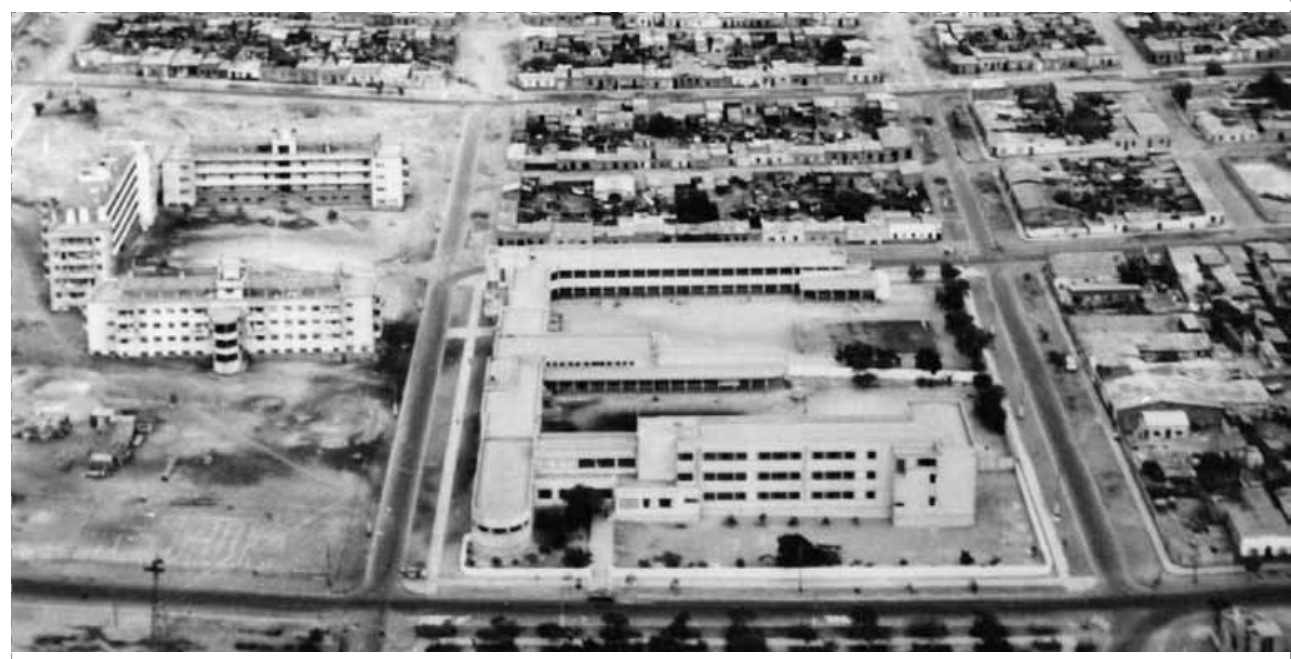

Colectivos Obreros, CSO0, 1939-42, y Grupo Escolar de Tocopilla, SCEE, 1940-1943 (c) Archivo [. Galeno. 
Grupo Escolar Nº 3 de Antofagasta, SCEE, 1939-1943. (2) El Mercurio de Antofagasta.

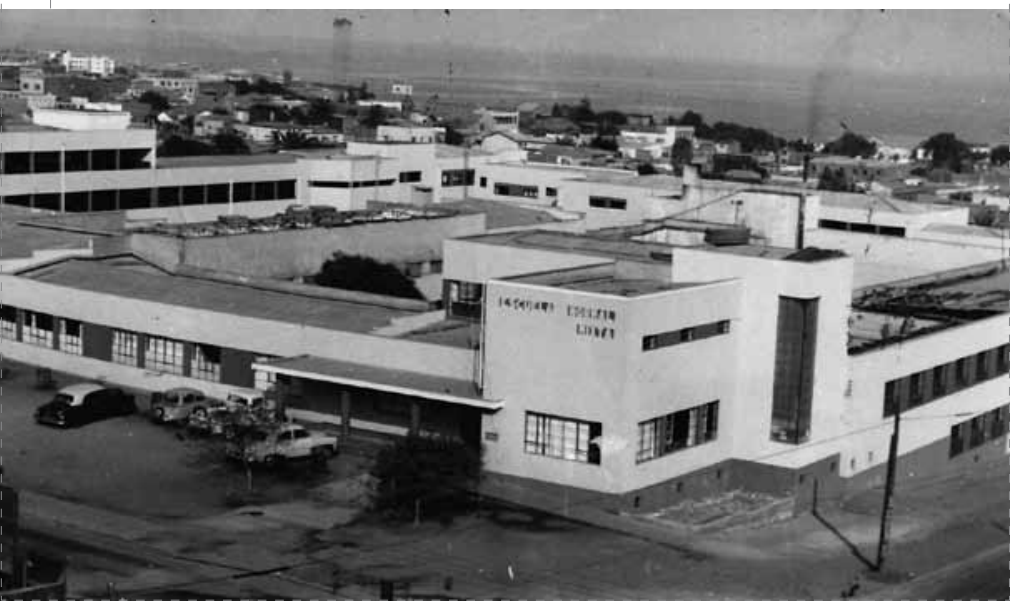

Grupo Escolar Norte, Antofagasta SCEE, 1960-1961. - El Mercurio de Antofagasta.

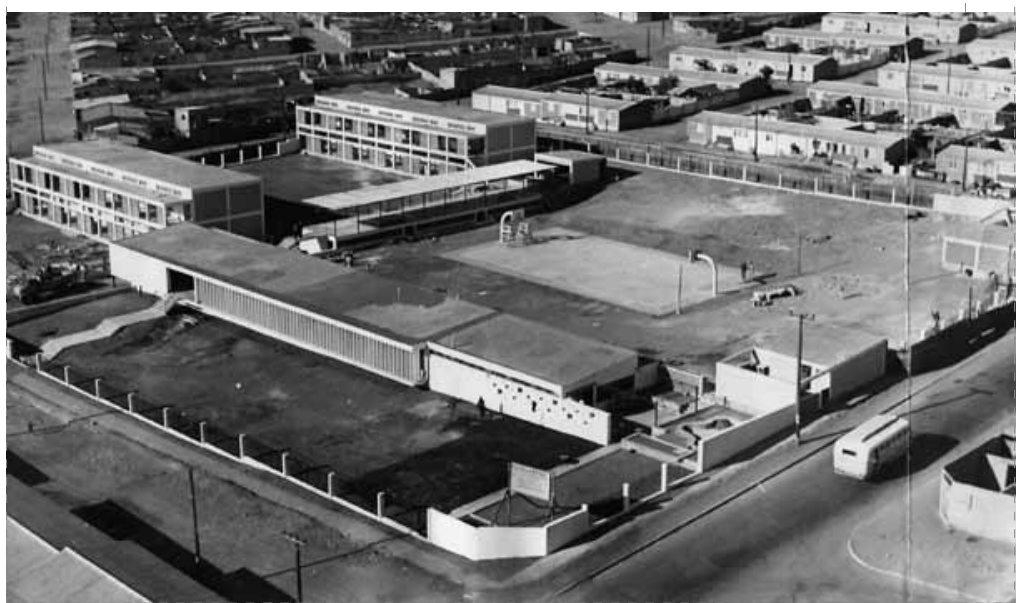

precedentes en el aspecto social para cuatro ciudades del norte, personifican también la proyección ideológica sobre la adecuada habitación colectiva del arquitecto Luciano Kulczewski7. Los edificios proyectados en 1939 como un modelo de vivienda colectiva en bloques, fueron construidos en Arica, Iquique, Tocopilla y Antofagasta, con variaciones en la disposición, y próximos al centro urbano de cada una de las ciudades, como indicaba Kulczewski, terminándose las obras entorno a 1942. Las obras formaron parte de un plan llevado a cabo por el arquitecto mientras fue, durante un año, el Administrador de la Caja de Seguro Obrero Obligatorio ${ }^{8}$. Los edificios consolidaban una arquitectura socialista que coincidía más con los ideales de las vanguardias rusas ${ }^{9}$ que con las obras que realizaba la Caja de la Habitación Barata.

La ciudad de Tocopilla sintetiza muy bien este principio de modernidad, por haber configurado un barrio donde se sitúan: la Beneficencia Pública, con el Hospital de 1938-1940, la Caja de Seguro Obrero con los colectivos desde 1939 a 1942, y el Grupo Escolar (E-3 y E-12, Arturo Prat y Pablo Neruda) de la SCEE, 1940-1943. El área,

Luciano Kulczewski. Discurso del delegado chileno. D. Luciano Kulczewski, administrador de la Caja de Seguro Obrero Obligatorio, en el Primer Congreso de la Vivienda en Buenos Aires. Revista Acción Social 1939; 82: p. 7

Gracias a la relación y colaboración política con el Presidente Pedro Aguirre Cerda.

Claudio Galeno. Edificios Colectivos para Obreros. L Caja de Seguro Obrero Obligatorio y la arquitectura social de Luciano Kulczewski en Antofagasta, Chile. Revista Cuadernos de Arquitectura. Habitar el Norte, $N^{\circ} 10$, Antofagasta: Departamento de Arquitectura, UCN, 2006, pp. 23-28.

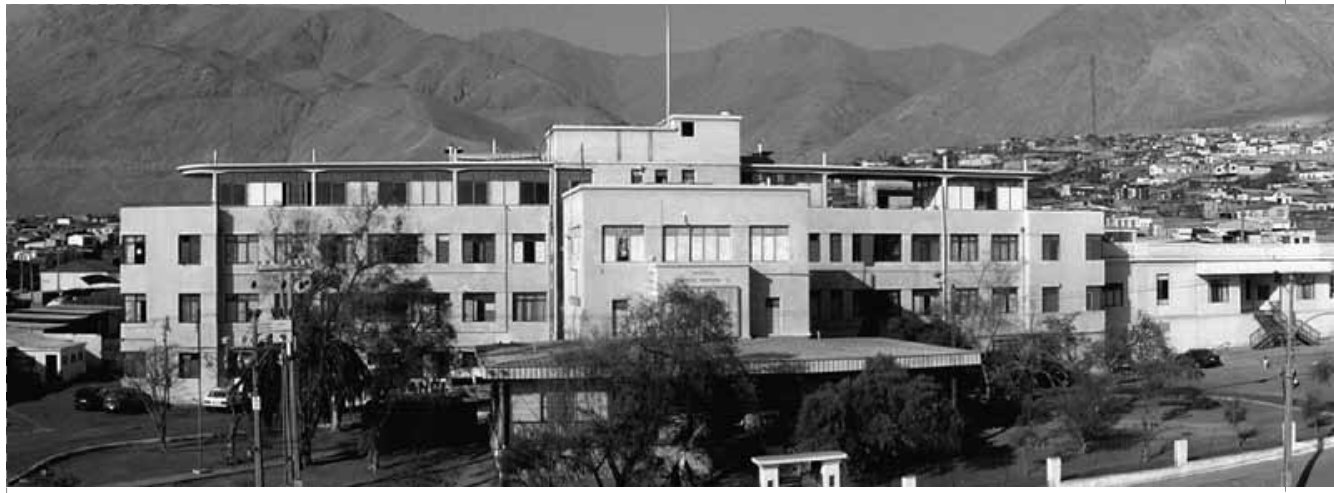

Hospital de Beneficencia de Tocopilla (Marcos Macuada), arquitecto Fernando Devilat، 1938-1940. () Archivo Claudio Galeno.

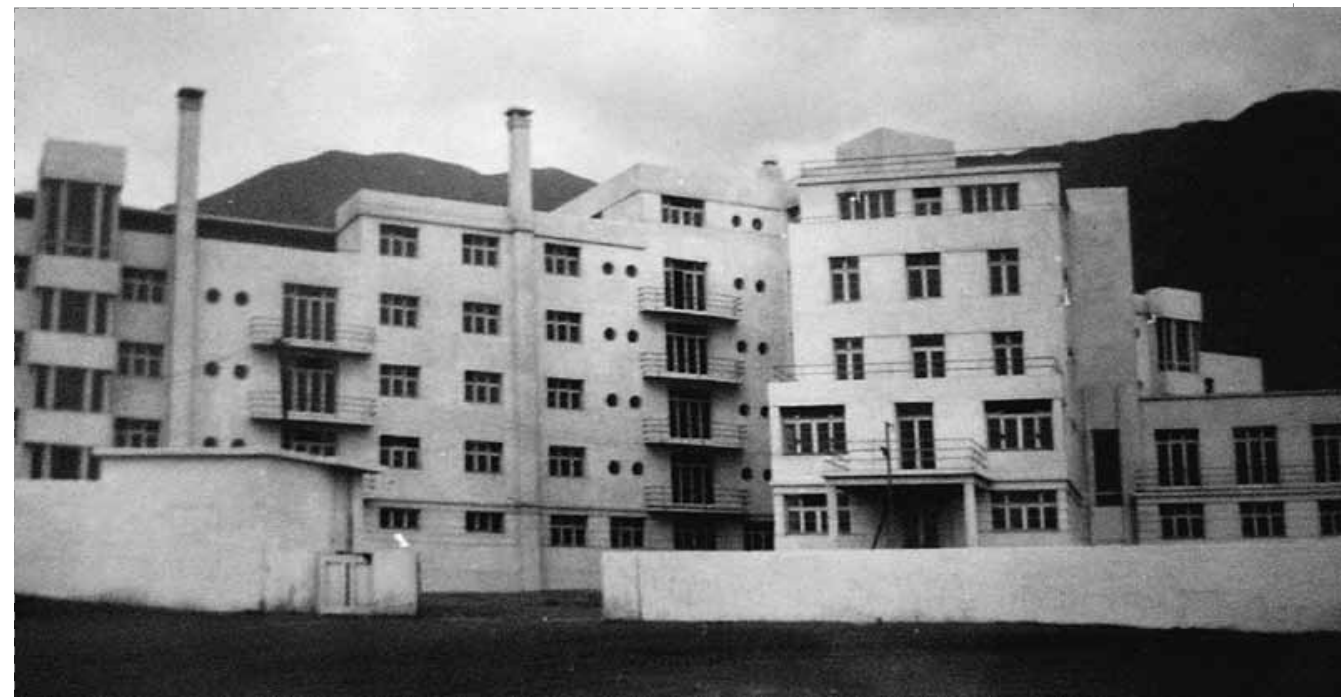

Hospital de Beneficencia de Iquique (demolido), 1936-1940. Foto Alfonso Campusano (c) Archivo Claudio Galeno. 
que se había iniciado con el acceso al estadio municipal, de 1931, en un experimento art deco americano, se completa con una torrereloj ${ }^{10}$ situado en el parque de la avenida 18 de septiembre, realizado en 1955, y el bloque con celosías del Liceo Domingo Latrille, c. 1960 ${ }^{11}$

Otra de las instituciones que dejó impronta en la renovación del norte, fue la Sociedad Constructora de Establecimiento Educacionales, con una serie de obras realizadas por los arquitectos Gustavo Mönckeberg y José Aracena, con patrones de resolución más racionales y estéticos que medioambientales. En Antofagasta produjeron un fuerte impacto innovador con el Grupo Escolar N³, 1939-1943, el que luego se convirtió en Escuela Normal y de Aplicación en 1945, con un anexo para el Internado en 1948. La particularidad de este grupo de edificios, con respecto a las construcciones de la SCEE, es la adaptación de lenguaje moderno de Mönckeberg y Aracena a un terreno con una significativa pendiente, donde los edificios, junto a sus dos patios centrales, se escalonan, articulando escalas del entorno y el programa.

Posteriormente en los años 60, la SCEE declaraba realizar una arquitectura «zonal», referida a la adaptación de los edificios al clima de las diferentes regiones del país, así como el aprovechamiento de los materiales de la zona ${ }^{12}$. En ese plan se podrían mencionar otras obras de la Sociedad en Antofagasta como la Escuela Hogar N³5, de 1960, y el Grupo Escolar Norte, 1960-1961. El Grupo Escolar mencionado, aparece, incluso como ejemplo, en un catálogo editado por los 25 años de la Sociedad (1963), como una escuela mixta recién inaugurada adecuada al clima, con una magnífica foto con intenso contraste entre luz y sombra, de la galería exteriores a las salas con muros celosías, un afortunado espacio intermedio moderno.

En el área de la salud, actuaron de forma consecutiva la Junta Central de Beneficencia Pública ${ }^{13}$, el Departamento de Arquitectura del Servicio Nacional de Salud y la Sociedad Constructora de Establecimientos Educacionales, entidades que reunieron un importante grupo de arquitectos bajo la dirección del arquitecto Fernando Devilat

Hospital Regional de Antofagasta, SNS-SCEH, 1957-1967، arquitectos Alfredo Celedón. Hernán Aubert y Frank Fones. () El Mercurio de Antofagasta.
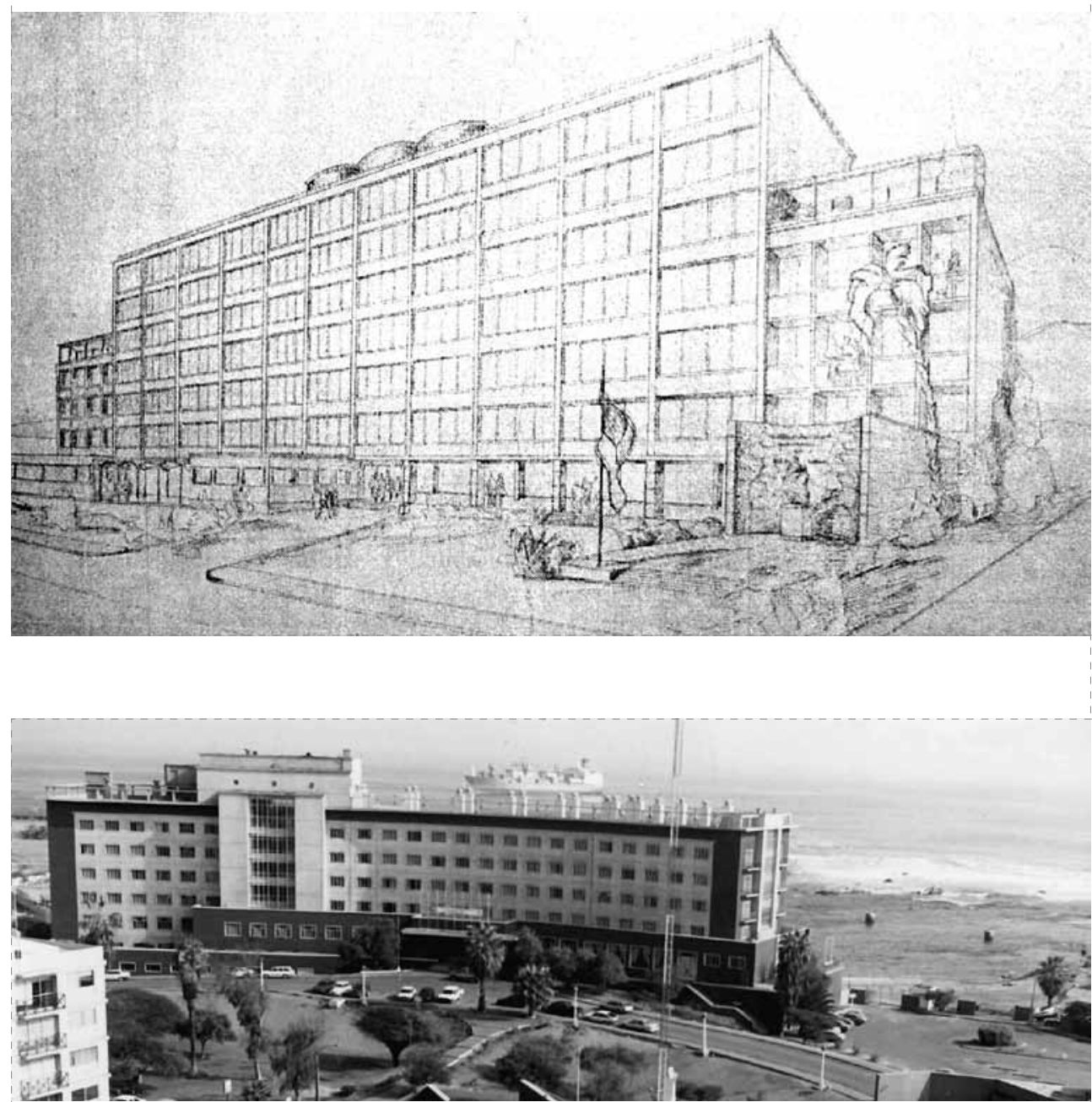

Hotel Turismo de Antofagasta, arquitecto Martín Lira, 1949-1953. Foto Glenda Kapstein. () Archivo Claudio Galeno.

Rocca. Una obra pionera, realizada por la Beneficencia fue el mencionado Hospital Marcos Macuada de Tocopilla ${ }^{14}$. Un bloque concentrado, hermético de tres niveles con un acceso cubierto para recibir vehículos y pacientes, en la parte superior concluye una terraza cubierta por una losa plana con remates curvos, propias de una primera modernidad. A ese precursor hospital, lo precede el Hospital de Beneficencia de
Iquique (actualmente demolido), construido entre 1936-1940, otro caso de edificio altamente concentrado en seis niveles, parte de la renovación hospitalaria e higienista que acompañaba la modernidad.

A partir de la creación de la Sociedad Constructora de Establecimientos Hospitalarios en 1945, se realizan renovaciones de hospitales en todo Chile, proyectadas por el

Donado por la Cámara de Comercio.

Giovanna Rossi Bizjak. Tocopilla, reseña histórica y desarrollo urbano. Tocopilla: Norgener SA, 1993

Sociedad Constructora de Establecimientos Educacionales (Chile), 25 años (29 de noviembre de 1937 / Sociedad Constructora de Establecimientos Educacionales). Santiago: Zig-Zag, 1963; p. 20

3 Bernardita Devilat. Notas para una visión patrimonial del Hospital San Juan de Dios. Punto de inflexión de la arquitectura moderna en Chile. Desafíos del patrimonio moderno. $2^{\circ}$ Seminario Docomomo-Chile. Edición Especial Revista Cuadernos de Arquitectura, Antofagasta: Departamento de Arquitectura, Universidad Católica del Norte, $2007 ;$ p. 100.

14 Gravemente dañado en el terremoto del 2007 ocurrido en Tocopilla. 
Departamento de Arquitectura del SNS, como en Arica ${ }^{15}$ y Antofagasta. El caso del Hospital Regional de Antofagasta ejemplifica muy bien la evolución de la arquitectura hospitalaria, ya no sólo dedicada a racionalizar servicios, sino de incorporar características del lugar, como la escala urbana y el clima. El edificio en tipología de bloque y base, fue proyectado a partir de 1957, por los arquitectos del SNS: Alfredo Celedón, Hernán Aubert y Frank Fones, construyéndose entre 1960 y 1967. En este caso, de una modernidad madura y arraigada, el edificio se organiza abierto, transparente y filtrado gracias a las favorables condiciones climáticas del emplazamiento.

Una cuarta institución que merece reconocimiento sobre su labor en el norte, fue el Consorcio Hotelero, posteriormente denominada HONSA. En 1944 se instituye el Consorcio con una singular característica, hasta entonces el turismo hacia el norte de la República no se había considerado, y los estatutos del nuevo Consorcio apuntan sus objetivos hacia el fortalecimiento de una moderna red hotelera en todo el norte de Chile, aprovechando la amabilidad del clima desértico costero.

En 1947 se inauguran los tres primeros hoteles construidos por el Consorcio: el Hotel Arturo Prat en Iquique, el Hotel Ovalle y el Hotel Francisco de Aguirre en La Serena, primer signo de su promisoria labor ${ }^{16}$. El arquitecto de esta institución fue Martín Lira Guevara, graduado en 1929 en la Universidad de Chile, aunque no el único, ya que otros arquitectos fueron contratados para realizar ciertos proyectos. Lira es autor de los proyectos de Ovalle y La Serena, posteriormente realizaría una de sus obras más emblemáticas y de mayor envergadura, el Hotel Antofagasta entre 1949-1953, seguirá con el Balneario de Los Vilos, 1953, la Hostería Cavancha, 1967-1969, en Iquique y el Hotel Bucanero en Coquimbo.

El Hotel Antofagasta, fue destacado internacionalmente por la calidad de su arquitectura y servicios que entregaba, es un singular ejemplo de arquitectura moderna enlazada al territorio, estableciendo la continuidad ciudad-arquitectura-paisaje, conceptos coincidentes con las ideas modernas de monumentalidad.

15 Realizado varias veces, así como el de Coquimbo debido a los sismos. El arquitecto Hernán Aubert participó en la primera versión del hospital de Arica y en las dos versiones del hospital de Coquimbo.

Mario Vergara. Política hotelera de la Corporación de Fomento. Revista En Viaje 1947; 168: pp. 36-37.
Hotel Bucanero, Coquimbo, Consorcio Hotelero de Chile, arquitecto Martín Lira Guevara. (c) Archivo Claudio Galeno.
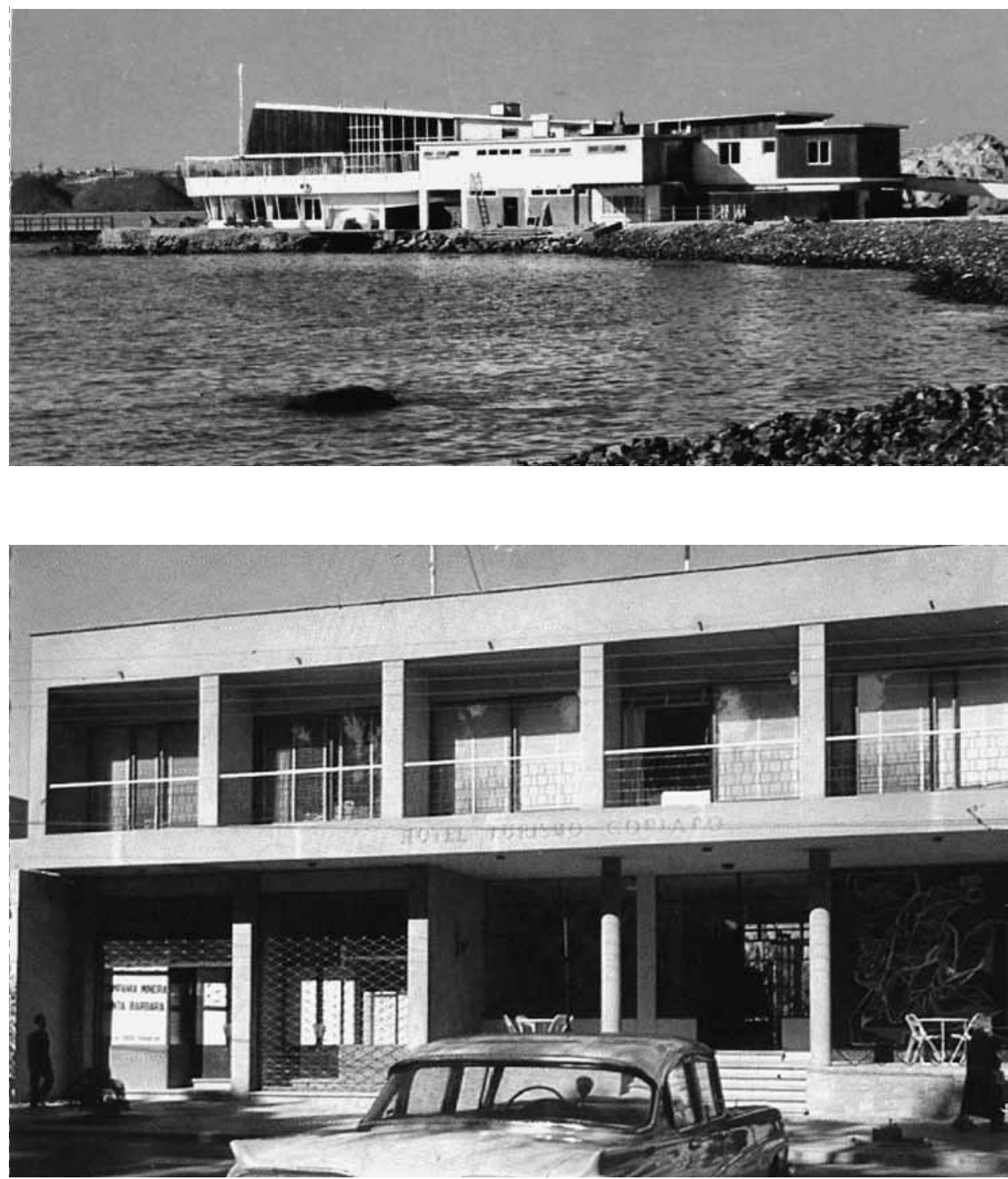

Hotel de Turismo Diego de Almeida en Copiapó, HONSA. () Archivo Claudio Galeno.

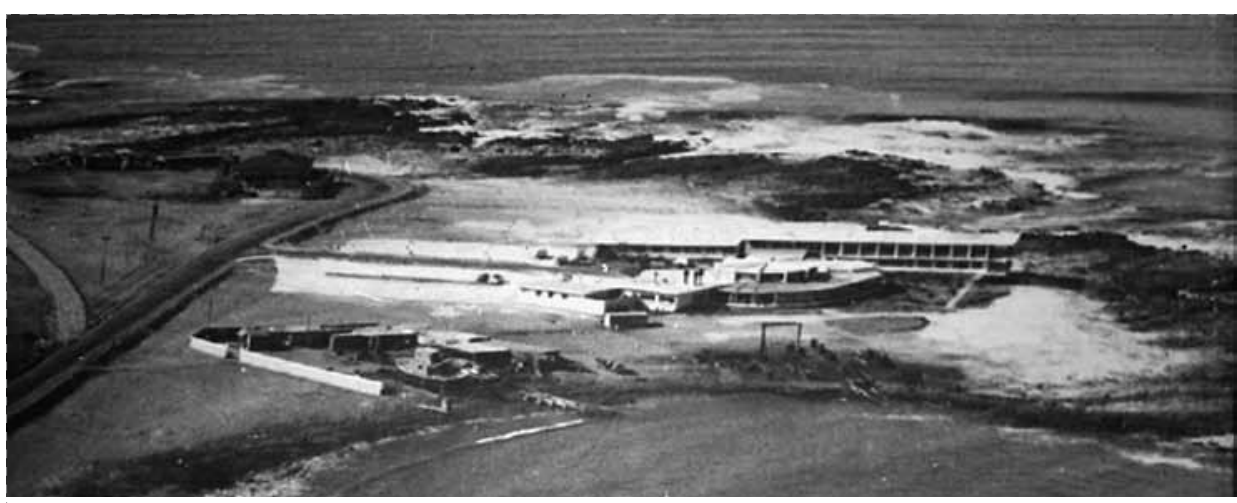

Hostería de Arica, HONSA. () Archivo Mauricio Galeno. 
Hostería de Chañaral, HONSA, 1960-1961, BVCH, arquitecto asociado J.A. Bravo. () Luís Ladrón de Guevara.

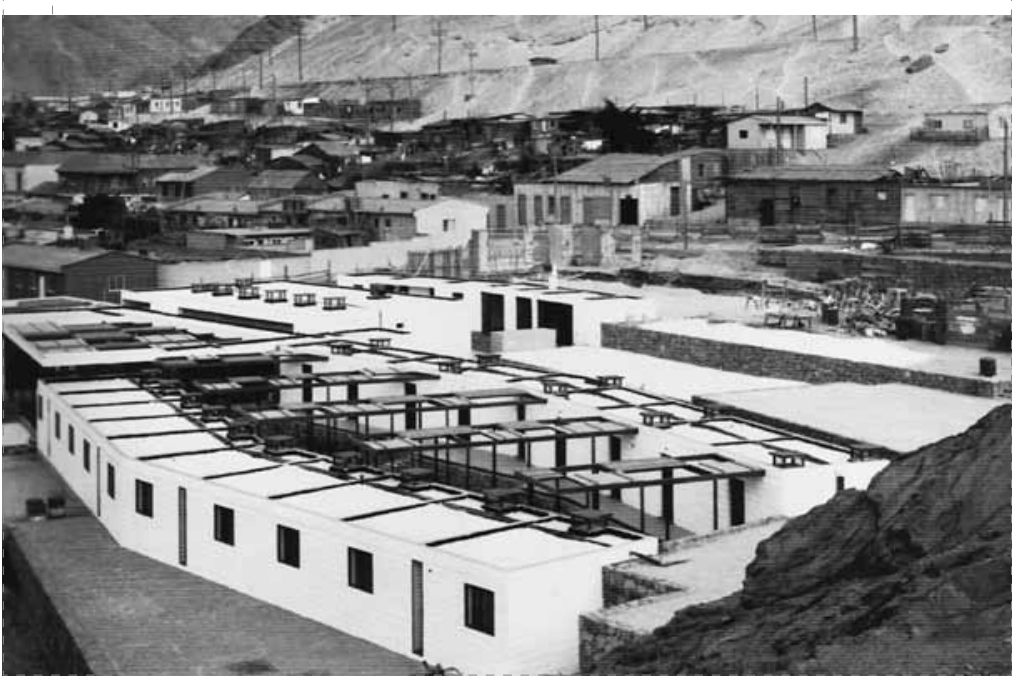

Edificio Plaza, Arica, arquitecto Gastón Saint Jean, 1960-1961.

( ) VVAA, Arica en el tiempo, 1980

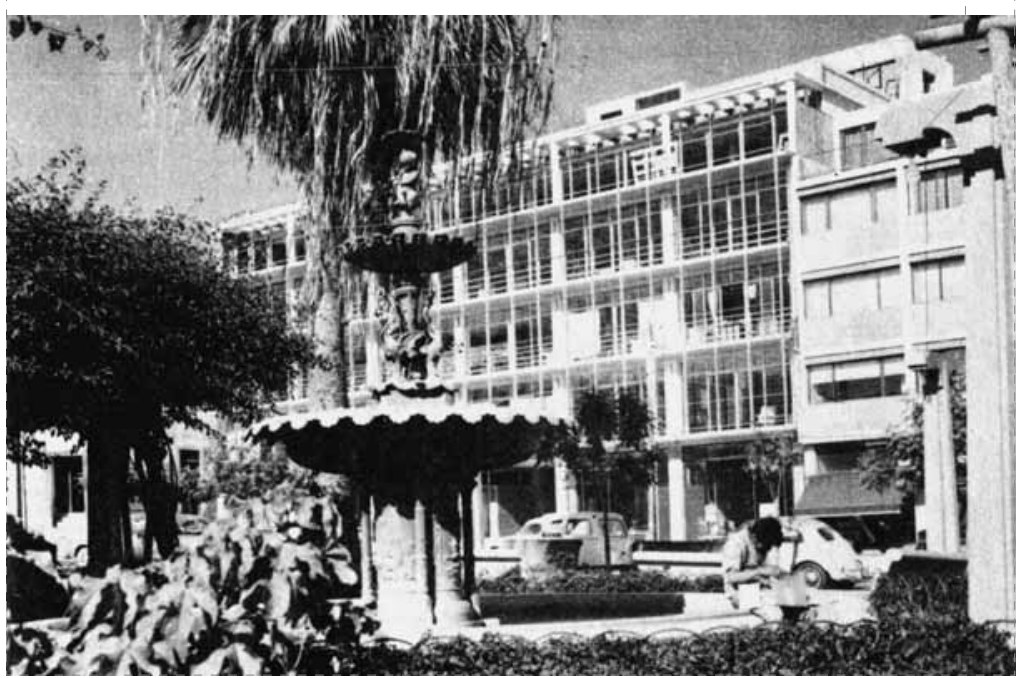

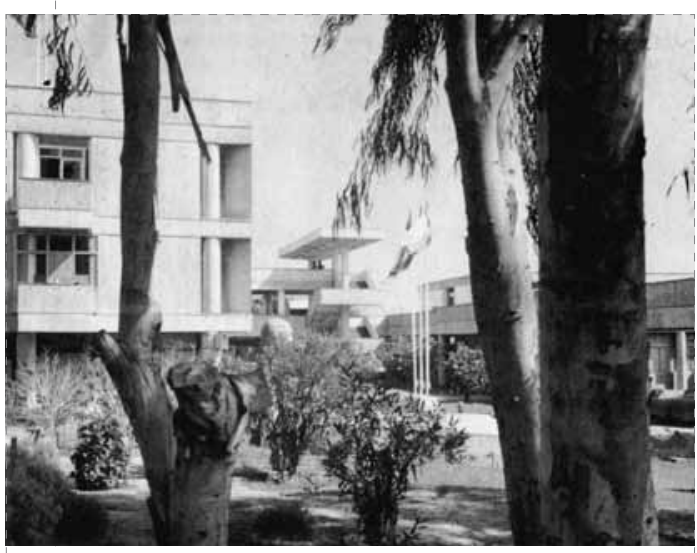

Campus Velásquez, Universidad de Chile Sede Arica (actual U. de Tarapacá). arquitecto Mauricio Despouy Recart, 1966 ๑) VVAA, Arica en el tiempo, 1980

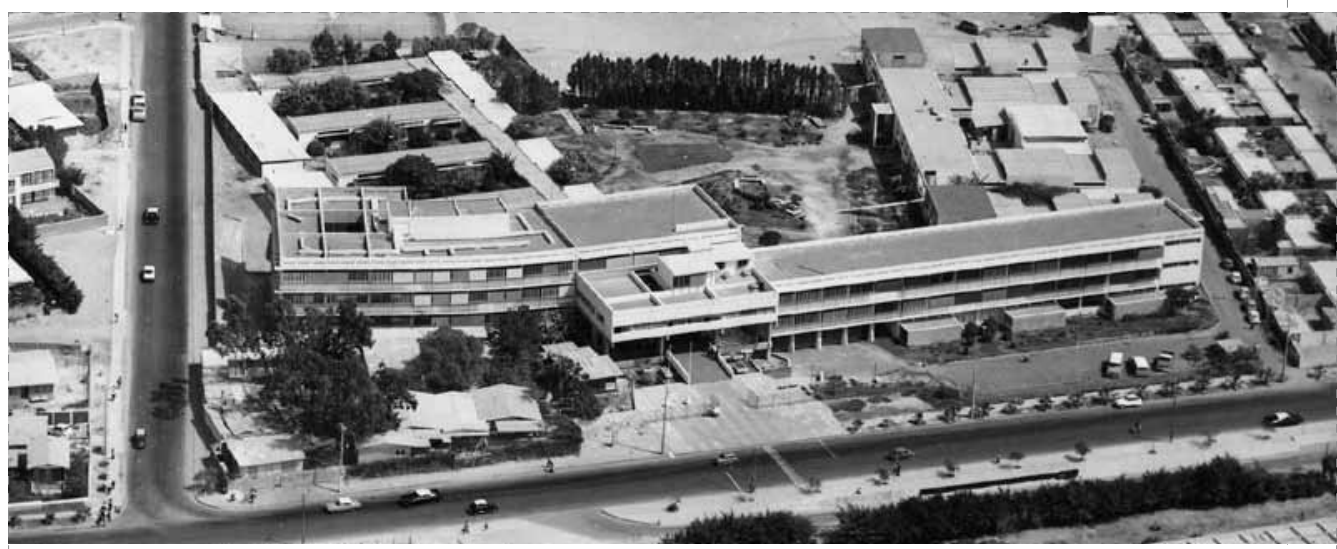

Campus Saucache, Universidad del Norte, Sede Arica (actual Universidad de Tarapacá) arquitectos Eduardo Garretón y Hernán Calvo, 1966-1967. @ DICOE-UCN
Subrayaría también la Hostería Cavancha por su reconocimiento y puesta en valor del paisaje. La Hostería realizada por Lira, es un peculiar edificio de tres piso, de una escala intermedia que reconoce el sitio donde se sitúa, el borde y un punto de articulación entre la playa y la península, produciendo un volumen que zigzaguea logrando diversas vistas sobre la playa.

El Consorcio también construye un Hotel de Turismo Diego de Almeida en Copiapo (demolido), la Hostería de Arica y el Hotel El Paso, 1956-1960, junto al Casino de Arica. Pero las obras de hotelería realizadas por HONSA, adquieren un matiz distinto a partir de fines de los años 50, hacia hosterías más modestas, que servirían para dar alojamiento a las personas que visitaban la zona por motivos de trabajo, descartando la construcción de grandes hoteles, completaron así una red de pequeñas hosterías en Taltal, Mejillones, Calama, Tocopilla, San Pedro de Atacama, Pica, Chañaral y Vallenar ${ }^{17}$.

Entre ellas destacan la Hostería de Chañaral como obra emblemática de los arquitectos Bresciani, Valdés, Castillo y Huidobro (BVCH), entre 1960-1961. Este proyecto de menor escala, con 20 habitaciones, recupera un grano y una dimensión propia del pueblo costero dispuesto en la pendiente, configurando un proyecto moderno de refinada organización regionalista.

Deteniéndose sobre las ciudades, la experiencia de Arica, fue uno de los lugares donde se consolidó una identidad moderna. En Arica hasta la construcción de los Colectivos Obreros por la CSOO, la ciudad contaba con una serie de edificios públicos emblemáticos de carácter ecléctico, y la construcción de los colectivos fue un signo de modernidad que preludiaba un anhelado desarrollo para la ciudad ${ }^{18}$.

Corporación de Fomento de la Producción - Chile, «Plan para el norte», CORFO, 20 años de labor, 1939-1959,

Santiago de Chile: CORFO, 1959; p. 118

18 Ciudades de Chile: Arica. Revista En Viaje 1944; p. 93. 

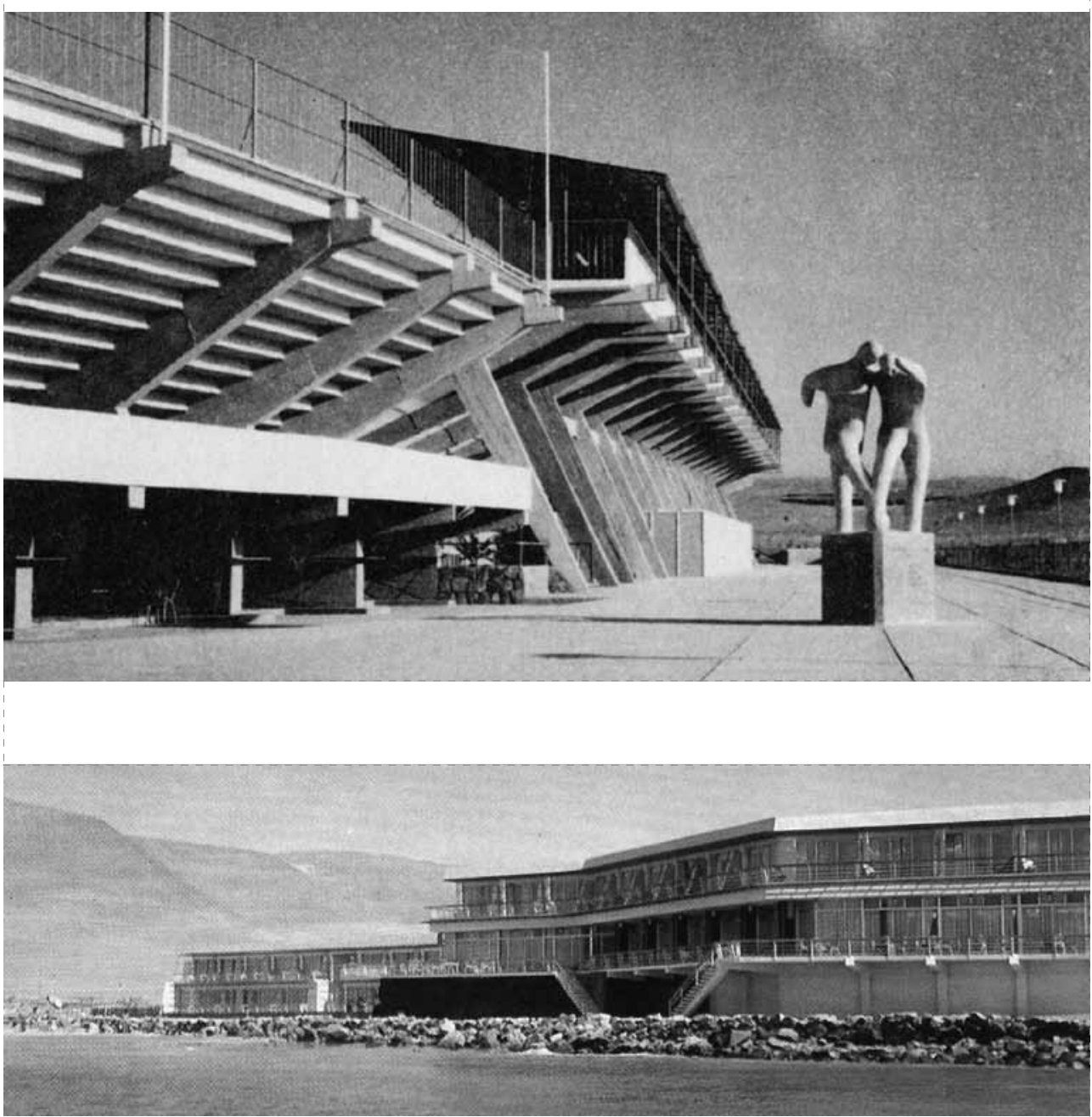

Postal Hostería Cavancha, Iquique, 1967-1969, arquitecto Martín Lira. (c) Archivo Claudio Galeno.

Pero su modernidad recién se consolida con la creación del Puerto Libre en 1953 y la Junta de Adelanto (JAA) en 1958, como una entidad estatal con autonomía de decisiones dedicada a fomentar el progreso económico y social ${ }^{19}$ que funcionó hasta 1976 . Su legado fue muy vasto y hasta hoy su nombre evoca progresismo. Las obras que promovieron, en su mayoría de gran escala, pasaron a hacer parte de una imagen urbana de renovación en clave racionalista.

Una de esas obras es el Edificio Plaza, construido por la JAA frente a la Plaza Colón, proyectada por el arquitecto Gastón Saint Jeann20, entorno a 1960-1961, es un volumen contenido entre medianeros, con cinco pisos, terraza superior y un espacioso teatro. El edificio fue el lugar donde funcionaron las oficinas de la Junta de Adelanto de Arica, así como otras reparticiones y locales comerciales ${ }^{21}$. Su arquitectura diáfana, orientada al norte, y filtrada gracias a su balcones y terraza cubierta, representa una arquitectura abierta, una modernidad de filtros para el medio ambiente ariqueño que encarna el ímpetu de adelanto que impregnó la ciudad durante los años de la JAA.

Entre las obras realizadas por la Junta, que permitían una arquitectura abierta aliada a la topografía y al clima, destacan las construcciones en el área de la educación, como las Campus Velásquez de la Universidad de Chile y el Campus Saucache de la Universidad del Norte22. La primera realizada por el arquitecto Mauricio Despouy Recart, en 1966, articula el programa en la pendiente a través de circulaciones que permiten conectar el entorno desde distintas escalas junto a una frondosa vegetación, resultando en una arquitectura de espacialidad integradora, donde la relación interior-exterior se desvanece. Mientras que el Campus Saucache de los arquitectos Eduardo Garretón y Hernán Calvo ${ }^{23}$, realizada entorno a 1966-1967 construye un borde que media entre el límite del espacio urbano y el desierto de Azapa.

En ese amplio espectro de obras modernas en Arica, algunas de la más reconocidas han sido los proyectos de la oficina Bresciani, Valdés Castillo, Huidobro, gracias a sus apropiados y reflexivos diseños. Cuentan entre esas obras el Conjunto Habitacional Chinchorro, 19551956, encargado por el gobierno como parte del inicial plan de desarrollo para la ciudad. Otros fueron encargados de la Sociedad Modernizadora de Arica (previo a la creación de la JAA), como el Conjunto Habitacional Ex-Estadio (construido parcialmente), 19561957, y el Estadio Carlos Dittborn, 1957. Mientras que el Casino de Juegos, realizado en colaboración con Gastón Saint Jean, entre 1960-1961, fue un encargo de la JAA.

19 Creada por la Ley 13.039 del 24 de septiembre de 1956, y disuelta por el Decreto ley N ํo 161.212 del 10 de diciembre de 1976. Fue llamada Ley de Arica, y otorgaba a la Junta de Adelanto el $15 \%$ de los impuestos de la internación de bienes en Arica al crearse un puerto libre.

20 Gastón Saint Jean Bate, tuvo bajo su dirección los jardines de la Piscina Tupahue en Santiago, 1960-66. También construye en Santiago, en 1971, el edificio Hotel Tupahue, junto con Héctor Valdés Ph. y Carlos García-Huidobro G. En Arica construyó la Población Lastarría, junto con los arquitectos Patricio Moraga y Jorge Vallejo, y la Escuela San José, en colaboración con Patricio Moraga, estos dos últimos proyectos fueron expuesto en la Revista AUCA, № 5 de 1966, dedicada al Norte Grande.

21 Hugo Ercilla Olea. Arica, un centro de atracción internacional. Revista En Viaje 1964; 374: p. 15.

22 También podemos incluir la sede de INACAP, proyectada por Jorge Aguirre Silva asociado a Enrique Echeverría, en 1965. Además Jorge Aguirre Silva realiza varia otras obras en el norte: la Caja de Crédito Popular de La Serena, en 1952; la Caja de Crédito Popular de Arica, en 1960; el Edificio de Seguro Social de Copiapó, en 1960; el edificio Banco Central de Iquique, con Hernán Mönckeberg, Enrique Echeverría y J. Briones, entre 1965-1970. en Jünemann Gazmuri, Alfredo, Jorge Aguirre Silva. Un arquitecto de movimiento moderno, Santiago de Chile: Ediciones ARQ, 1996

23 Quienes realizaron bloques de viviendas en una manzana diagonal en Antofagasta, entre el parque Brasil y la costanera. 
Ilustre Municipalidad de Iquique (demolido). (c) Archivo Claudio Galeno.

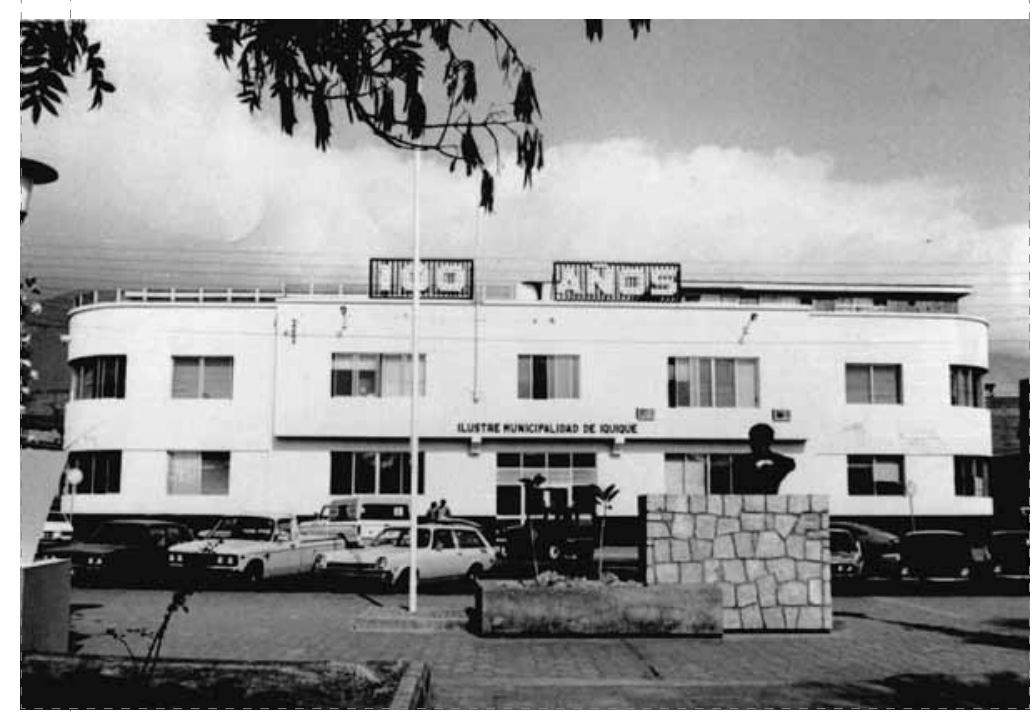

Gobernación Marítima de Iquique (demolido). (a Mauricio Galeno.

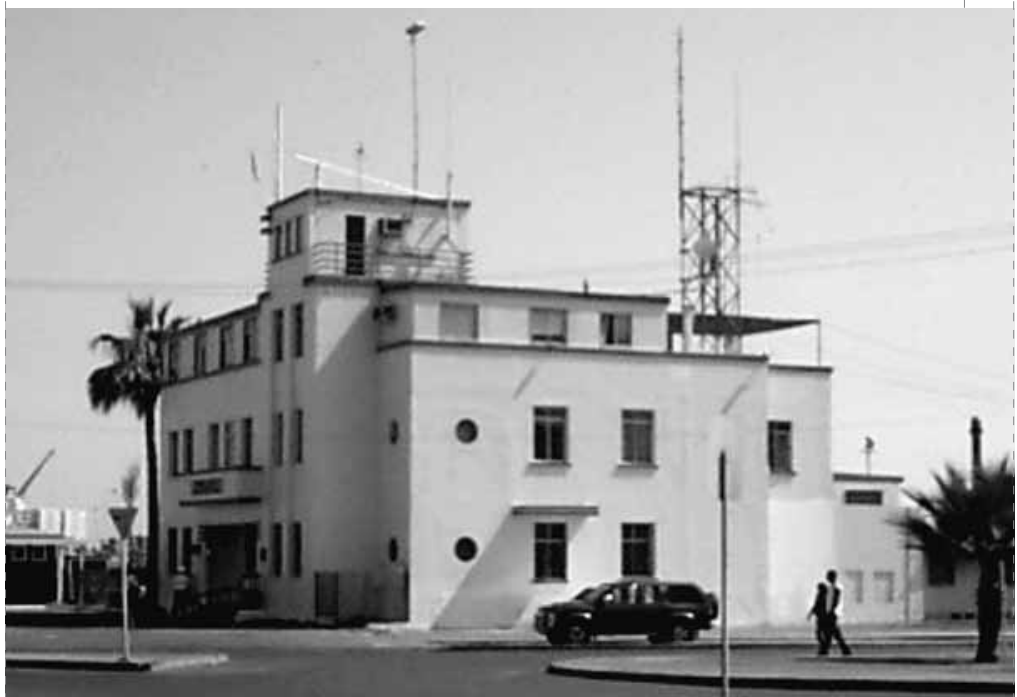

Por otro lado sería importante investigar la contribución y desenlace de Emilio Duhart, en la estructura urbana de las ciudades del norte chileno. El arquitecto, durante su últimos años en Chile participa intensamente en estudios y propuestas urbanas para Arica y Antofagasta. A partir de 1968, elabora un proyecto para Arica, denominado «Centro Urbano y Parque Antigua Aduana», en 1969 comanda un gran equipo para realizar un estudio urbano sobre Antofagasta, que apuntaría hacia un «desarrollo turístico de la costa de Antofagasta», mientras que en Arica elabora una proposición para un nuevo plan regulador del área central de la ciudad. Por último en $1970^{24}$ realiza algunos proyecto para la Junta de Adelanto de Arica (JAA) ${ }^{25}$

Iquique no es una ciudad radicalmente moderna, en gran medida debido a un período de depresión económica que vivió la ciudad desde la crisis del salitre hasta los años 50. A pesar de eso, la modernidad en lquique también legó un significativo patrimonio disperso por la ciudad que debiera ser reconocido y valorizado ${ }^{26}$, y que gradualmente se ha estado demoliendo ya que al parecer no coinciden con las actuales políticas de exacerbación de la identidad georgiana. Entre las obras demolidas están: el edificio de la llustre Municipalidad de Iquique y la Gobernación Marítima.

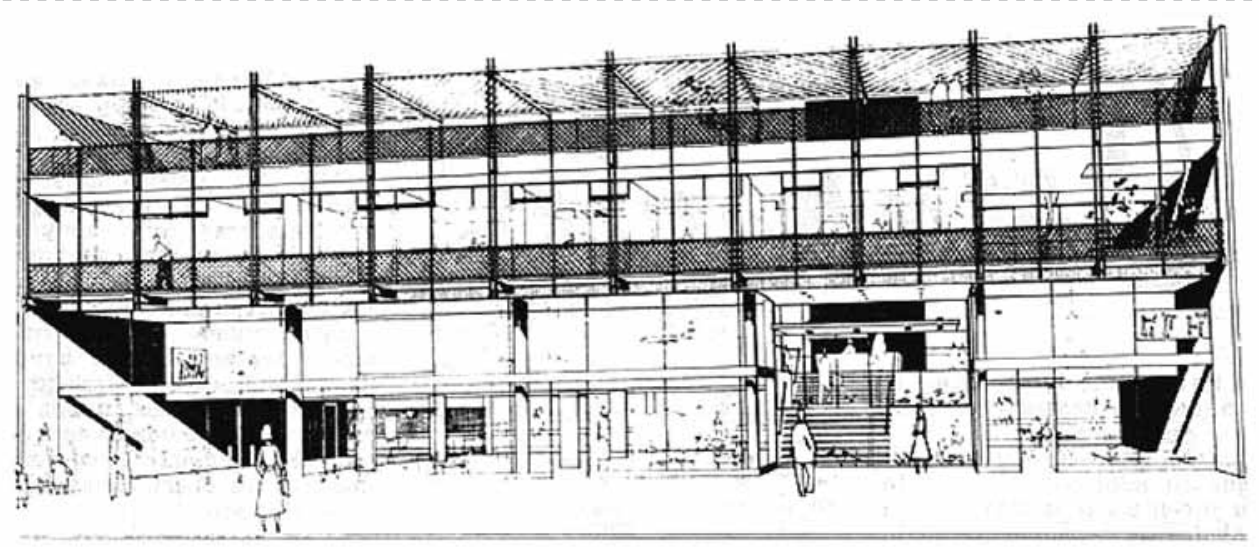

Edificio CORFO del Departamento de Tarapacá, Iquique, 1960-1962 arquitectos Luis Mitrovic y Sergio Miranda. () Revista En Viaje

Entre los edificios que sobresalen por su adaptación al clima, está principalmente el Edificio CORFO del Departamento de Tarapacá (actual Servicio de Impuestos Internos) en Iquique, 1960-1962²7, de los arquitectos Luis Mitrovic $^{28}$ y Sergio Miranda ${ }^{29}$, el cual expresa una preocupación por las respuestas de la arquitectura tradicional y un compromiso regionalista, con galerías que construyen sombra y una azotea en clave moderna, para amortiguar la radiación térmica y permitir la ventilación. De otra forma la organización espacial configura una alternancia de alturas y escalas, que permiten una secuencia espacial y transparencia entre las dos calles donde se sitúa.

Pero también existen otros casos de innegable valor, a pesar de sus resoluciones sean de una arquitectura más ortodoxa y tectónica, como

24 El mismo año ganó el segundo premio en el concurso para el Aeropuerto Internacional de Pudahuel.

25 Alberto Montealegre Klenner. Emilio Duhart arquitecto. Santiago de Chile: Ediciones ARQ, 1994

26 Jorge Cordano, Rodrigo Fuentealba. Arquitectura moderna en Iquique mucho que admirar. La Estrella de Iquique, 2005.

Publicado también en la revista AUCA 6-7 (octubre de 1966 - enero de 1967). Santiago de Chile: Ediciones AUCA; pp. 54-55.

28 Luís Mitrovic es autor junto a Emilio Duhart del edificio industrial para Carozzi en Santiago (1961).

29 Humberto Eliash Díaz, Manuel Moreno Guerrero. Arquitectura y modernidad en Chile (1925-1965). Una realidad múltiple. Santiago de Chile: Ediciones Universidad Católica de Chile, 1989; p. 189 
Plan de Remodelación del Área Costanera, publicado en AUCA N 5.

Santiago: Ediciones AUCA, 1966; pp. 60-61. (-) Revista AUCA.

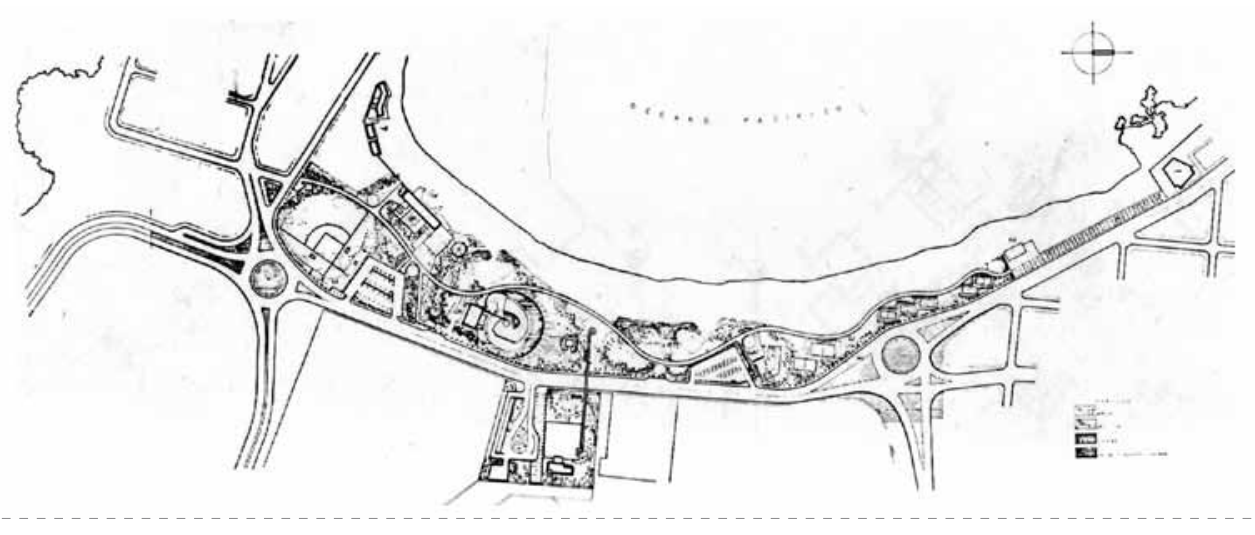

Cine Délfico (demolido) I quique, 1966-68. (c) Archivo Mauricio Galeno.

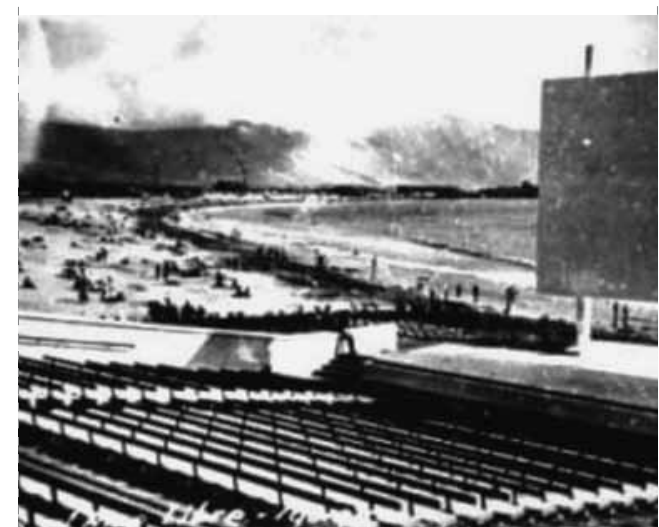

los Colectivos Obreros de la CSOO, 1939 1942; la Escuela Superior de Niñas (E-75), de Mönckeberg y Aracena, $1942^{30}$; el Hotel Prat, 1947; el Edificio del Servicio de Seguro Social (actual INP); la Ferretería Las Dos Estrellas; el Liceo A-11 (Elena Duvauchelle); la Escuela Normal de Artesanos (actual Liceo Politécnico A-9), c. 1944-1948; el Ex-Banco Central, de Jorge Aguirre Silva, Hernán Mönckeberg, Enrique Echeverría y J. Briones, construido entre 1965-1970; la Prefectura de Carabineros, el más diáfano de este grupo; e edificio del Ex-Banco de Concepción, de los arquitectos Héctor Martínez, Carlos Aguilar y Héctor Ruiz, en 1966; y el interesante y complejo experimento con bloques de vivienda denominado La Puntilla.

En Iquique a partir de 1966 se realiza un extenso plan que incluye un conjunto habitacional denominado Remodelación del Morro de la CORVI, proyectada por los arquitectos Orlando Sepúlveda y Roland Vaca, en 1966. El plan maestro contemplaba la remodelación del área costanera, proyectada por el exitoso Grupo TAU, compuesto por los arquitectos Sergio González, Gonzalo Mardones, Julio Mardones, Jorge Poblete y Pedro Iribarne.

El proyecto incluyó entre su obras (hoy casi todas demolidas): la Plaza Balmaceda, sector conocido como «Las Urracas»; el Cine Délfico, 1966-1968, un innovador cine teatro al aire libre; el Club San Remo (Casino), 1969-1970; subsistiendo actualmente solo la Hostería Cavancha, 1967-1969, realizada por Martín Lira para HONSA.

30 Alfredo Jünemann. Arquitectura del inicio del modernismo. Oficinas G. Monckeberg y J. Aracena y la arquitectura educacional 1920-1950, Chile, Proyecto DIPUC 99/09C, Pontificia Universidad Católica de Chile, 2000.

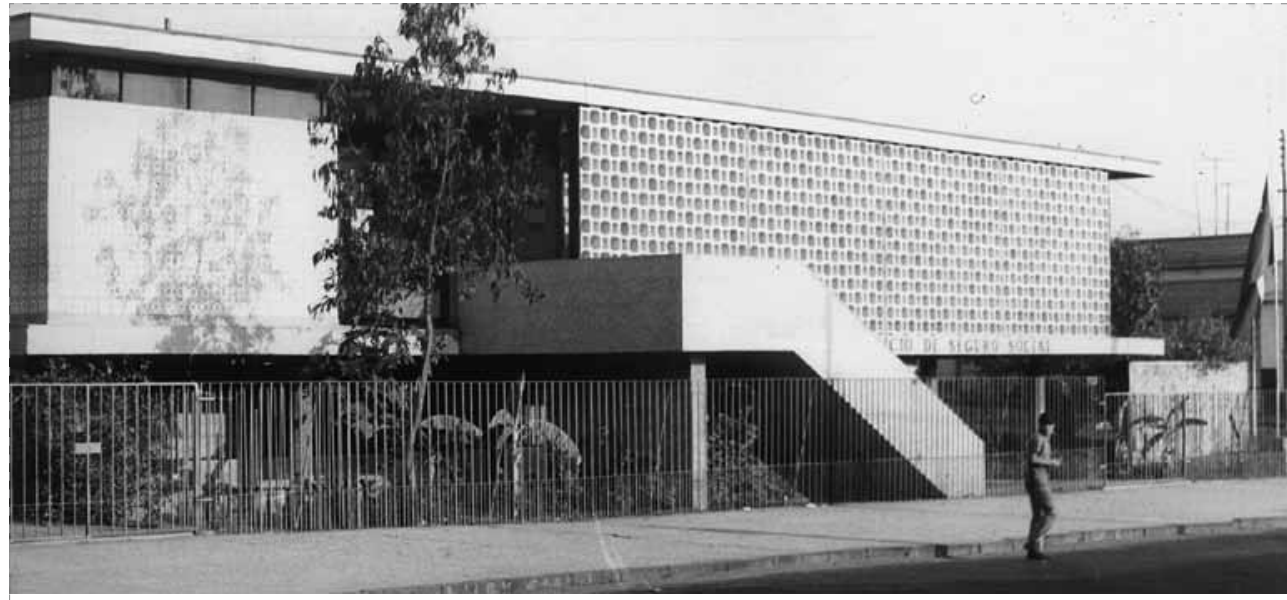

Servicio de Seguro Social de Antofagasta (demolido), BVCH, 1960-1961. (c) El Mercurio de Antofagasta.

Sobre la modernidad en Antofagasta, mucho interés ha despertado la obra de BVCH, para el Servicio de Seguro Social, 1960-1961 actualmente demolido. El edificio que salvaba una pendiente homogénea, se valía de aquellos principios básicos de la modernidad, apropiados para el clima desértico de esa ciudad. El uso del pilotis elevaba el edificio esquina y articulaba el programa en la pendiente. Muros de celosías y un patio interior domesticaba la excesiva luminosidad del ambiente y creaban espacios intermedios.

Otro edificio resuelto para el lugar y clima es la Intendencia y Servicios Públicos, realizada por el arquitecto Edwin Weil Wohlke, en 1958 También con el uso de pilotis crea un espacio público de acceso que suspende el bloque de servicios definiendo un amplio espacio público sombreado, mientras que los niveles superiores en planta libre, la luz se controla a través de quiebra soles que le entregan un fuerte carácter al edificio.

Un proyecto difundido, fue el Colegio Universitario Regional, sede de la Universidad de Chile, fruto de un concurso realizado en 1962 y construido hasta 1963, por los arquitectos Iván Godoy, Kurt Konrad, Alberto Sartori, Guillermo Schenke, German Wignant y Vicente Bruna. El Colegio Regional deriva de un estudio sobre el desierto, donde la idea de claro oscuro adquiere preponderancia gracias a la construcción de un gran alero y de una calle subterránea en semipenumbra, en la claridad de la biblioteca (actualmente demolida), y en un balcón sobre el casino, un edificio desde donde se permite descubrir el mar, y donde «el hombre se sentirá en un oasis bajo los edificios, cortando violentamente la luz con la sombra». 
Intendencia y Servicios Público de Antofagasta,

arquitecto Edwin Weil Wohlke, 1958. () Archivo Claudio Galeno.

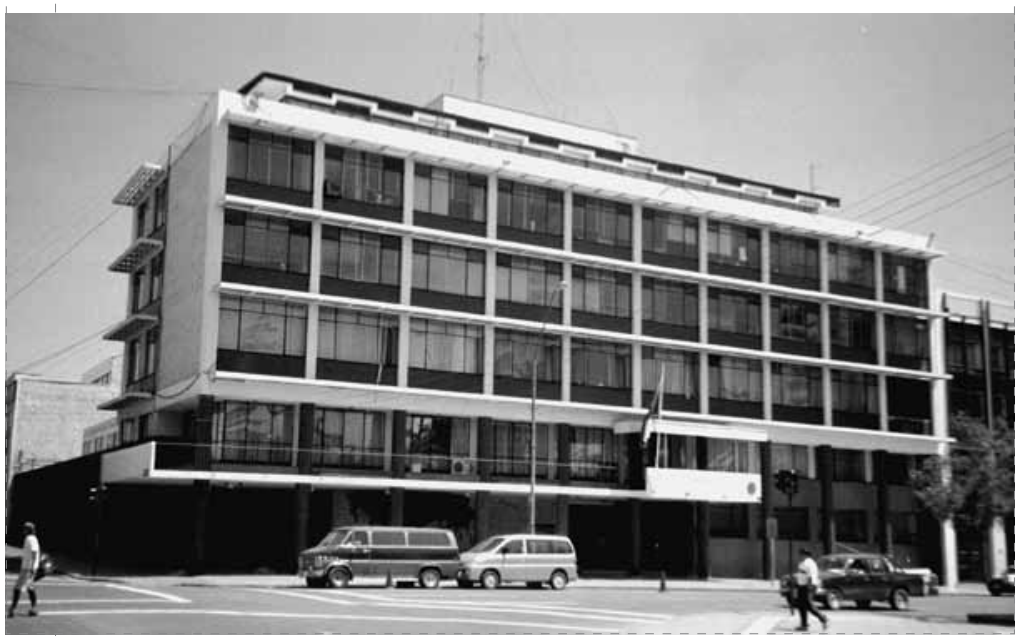

Colegio Regional de Antofagasta, sede Universidad de Chile Biblioteca (demolida), 1962-1963. () El Mercurio de Antofagasta

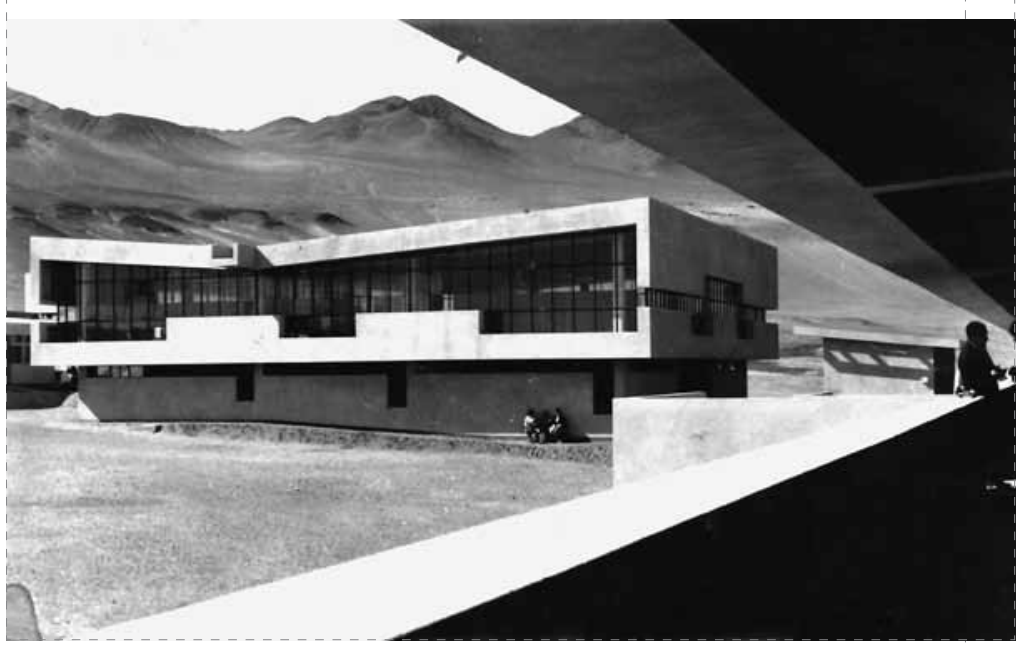

En el marco de las oficinas de arquitectura privadas en el norte, destacan en Antofagasta la extensa obra de dos arquitectos graduados en la Universidad de Chile: Alfonso Campusano Núñez, graduado en 1926 , desarrollando obras relevantes con una estética depurada hacia el estilo buque, como la sede del Instituto de Fomento Minero e Industrial de Antofagasta, en 1937, el Colegio San Luis en 1945, o la Casona Castro Toro (demolida), de 1948; y Jorge Tarbuskovic Dulcic, graduado en $1934^{31}$, quien siendo original de lquique se traslada a Tocopilla como Director de Obras Municipales y luego a Antofagasta, desde donde desarrolla una extensa labor en toda la región, con obras que demuestran una exploración sobre diversas expresiones estéticas de la modernidad: en aspecto náutico, como el edificio conocido como el Casino del Balneario, de 1937, y el Pabellón de Turismo (demolido), 1939-1949, la búsqueda neocolonial en algunas casas desarrolladas durantes los años 40 en paralelo a otras obras de líneas más puras, como el Gimnasio Club de Deportes Hrvatski Sokol, 1949-1966, hasta Ilegar a una producción más expresionista de los años 60 y 70, como el edificio doble para la $2^{a}$ y $4^{a}$ Compañía de Bomberos, 1967-1973.

Pero entre los arquitectos residentes, destaca la figura del arquitecto Ricardo Pulgar San Martín, quien se graduó en la Universidad Católica de Chile, en 1949, al año siguiente se traslada a Antofagasta, donde trabajó en un principio realizando proyectos para la Caja de

A Jorge Tarbuskovic, a pesar de que se haya recibido en 1934, se le atribuyen los diseños de las plazas: Condell en Iquique (actualmente con alteraciones), y Condell de Tocopilla en 1931.

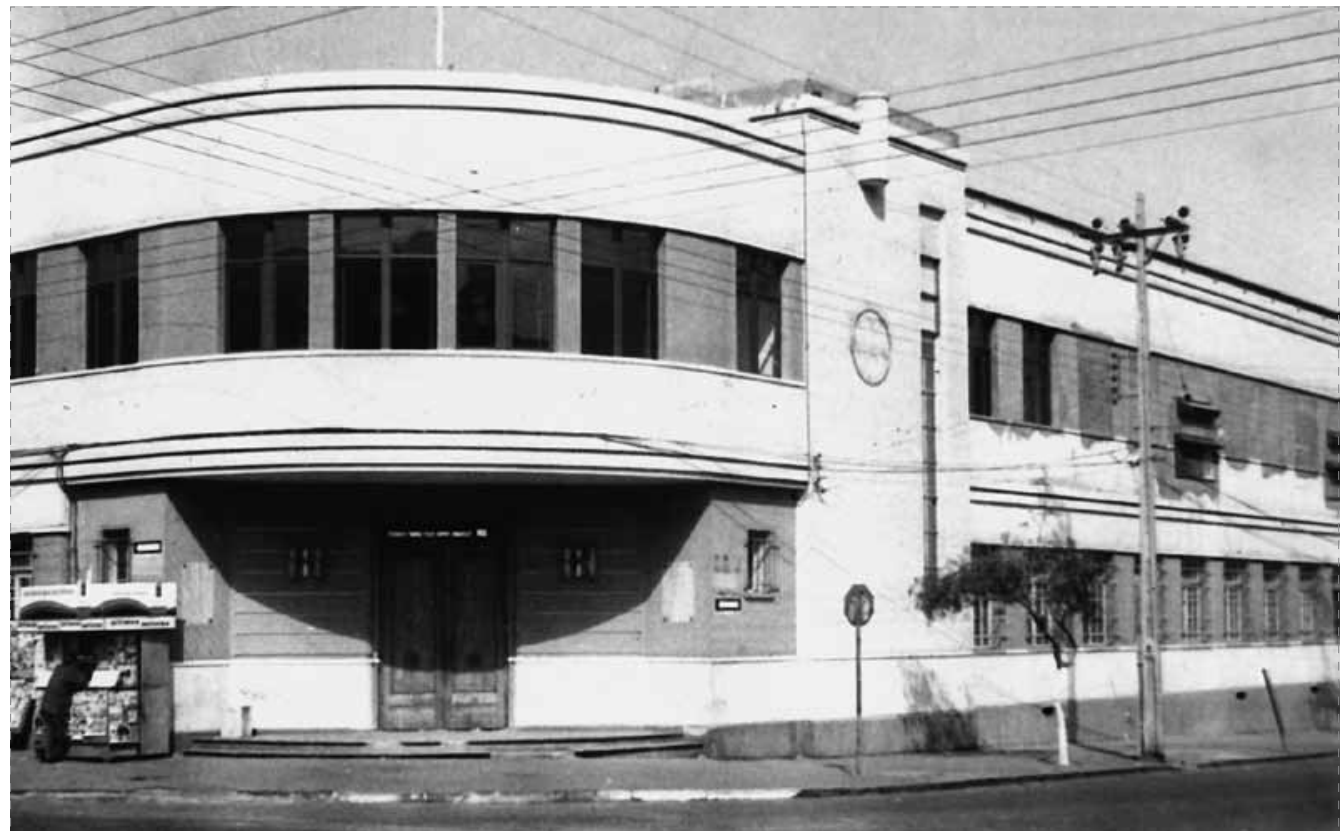

Instituto de Fomento Minero e Industrial de Antofagasta, Alfonso Campusano Núñez, 1937 (c) El Mercurio de Antofagasta.

EE.PP., para luego asociarse a Edmundo Pérez Zujovic y a su empresa constructora en 1954 , construyendo en todo el norte de Chile.

A Ricardo Pulgar se le puede describir como un arquitecto con una capacidad incansable y visionaría como ningún otro en el norte. Su arduo trabajo y buenas relaciones políticas hicieron prosperar una empresa que se posicionó por la calidad de sus obras. En Antofagasta podríamos mencionar edificios emblemáticos, como la Agencia de la Caja de
EE PP , 1954-1958, para quienes trabajó en un principio, el Edificio Plaza Colón, 1955-1960, los Colectivos de la Caja de EE.PP., 1949 1956, pero sin duda la más importante de ellas es el Conjunto Habitacional Gran Vía, que se formula como una urbanización moderna resultado de una sociedad EMPART, creada a partir de 1955, y que se concluye en 1978 . Entre los edificios que componen la Gran Vía existen dos edificios lineales que se adecuan a la topografía y articulan escalas de barrio y territorio, son el Huanchaca (conocido como 
Balneario de Antofagasta, al fondo Casino del Balneario, 1937. arquitecto Jorge Tarbuskovic Dulcic. O El Mercurio de Antofagasta.
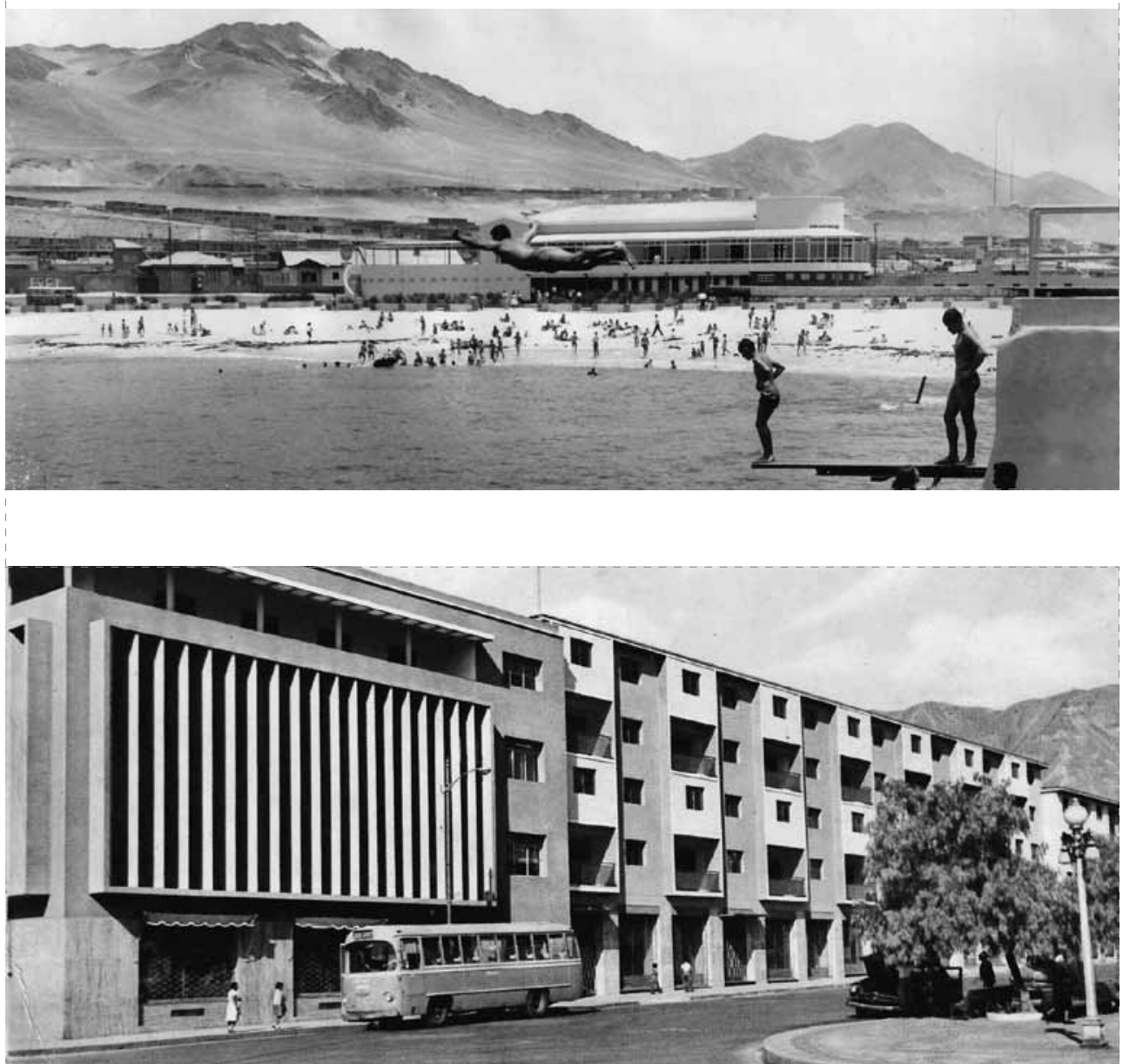

Agencia de la Caja de EE.PP., 1954-1958, y Edificio Plaza Colón, 1955-1960. Antofagasta, arquitecto Ricardo Pulgar San Martín, Constructora Edmundo Pérez Zujovic.

(c) Archivo Claudio Galeno.
Curvo), 1967-1970, y el Caliche, 1970-1974. Ambas construcciones organizan el entorno acentuando y densificando el barrio, y creando conectividad a través de vías elevadas, terrazas-balcones y escaleras, definiendo una espacialidad integradora que convierte el territorio en arquitectura.

Pero en Antofagasta, varios otros arquitectos también estuvieron realizando obras de interés, algunos representaban nuevas generaciones que continuaron el legado de Campusano, Tarbuskovic y Pulgar, por ejemplo: Alejandro Crestá Gouyou, autor del demolido Terminal de buses Macaya Cavour (posterior Tramaca), 1966, y del constructivista Sindicato de Estibadores Marítimos, 1968-1971; Sergio Puebla Leeson con las Salas de Clases, 1961-1962, y Rectoría, 1964-1965, de la Universidad del Norte; Óscar del Pozo; Pedro Letelier, con la Casa Martinic, 1947-1949;

Mario Reyes, con la Molinera del Norte, 1963, por mencionar algunos y ciertas obras.

Introduciéndose en los asentamientos mineros de la Región de Antofagasta, se puede observar que la diversidad urbana de Chuquicamata denota un complejo proceso con diversas formas y tiempos de modernidad. Sin embargo edificios como el Teatro Chile, del arquitecto Enrique Cooper, 1943, o el Auditorio-Teatro del Sindicato de Alejandro Crestá Gouyou y Luis Lira, de 1959-1961, se podrían alinear con una serie de interesantes teatros situados también en asentamientos mineros declarados monumentos históricos, como el Teatro de Chacabuco, 1924, el Teatro de Pedro de Valdivia, 1937 y el Teatro de María Elena, inaugurado en 1948.

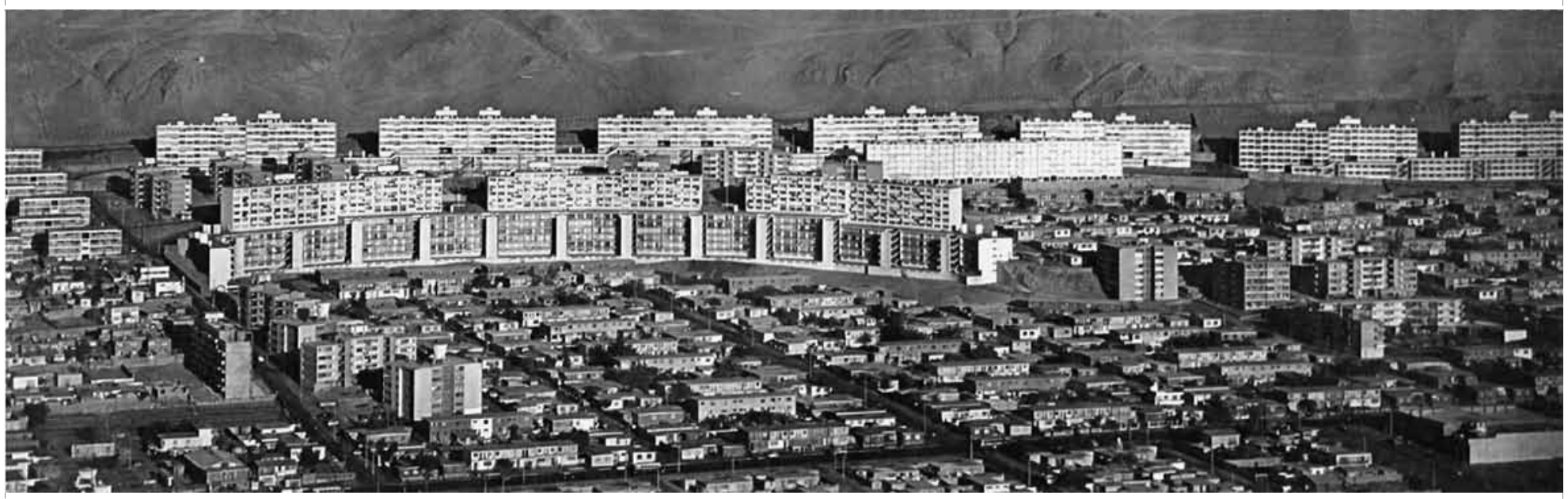

Conjunto Habitacional Gran Vía, Antofagasta, Edificios Huanchaca, 1967-1970, y Caliche, 1970-1974, arquitecto Ricardo Pulgar. (c) Catálogo Constructora Edmundo Pérez, 1976 
El reconocimiento del confinado patrimonio moderno del norte de Chile, requiere de difusión e investigación. En ese sentido es importante la labor de reconstrucción histórica de estas obras, para poder difundir y reclamar su rol en la memoria, creando estima en la actual comunidad obsesionada por lo nuevo, por lo instantáneo y fugaz.

En general las obras modernas en el norte pasan por dos grandes etapas, una más ortodoxa y tectónica, de obras que colonizan y tienden a mejorar racionalmente las condiciones de vida a través de salud, ocio, educación y vivienda, y una etapa posterior donde los arquitectos se aventuran en una experimentación conducente a una arquitectura abierta. Las estrategias de arraigo a través del reconocimiento de los valores del territorio por medio de la arquitectura nos dejó un significativo legado arquitectónico que no puede ser desconocido. Muchos edificios han construido lugar uniendo lo natural con lo artificial, dramatizando, recreando o inventando la vida en el desierto, pero de sus valores se han producido pérdidas importantes.

Son diversas las sociedades, las culturas y las estructuras urbanas donde se insertan este patrimonio reciente, mientras Arica mantiene relativamente intacto el legado de la modernidad, en Iquique se desconoce y en Antofagasta se está redescubriendo.

En el advenimiento de la modernidad para el norte de Chile, fue estratégica la exploración sobre las particularidades del territorio desértico. De esa forma la arquitectura moderna consolidó espacios que incorporaban el entorno. Realizándose arquitecturas que, dialogando con las singularidades de cada lugar bajo un lenguaje moderno, incrementaron la pertenencia e identidad de la progresista sociedad nortina durante el siglo xx.

\section{Bibliografía}

Max Aguirre. La arquitectura moderna en Chile. El cambio de la arquitectura en la primera mitad del siglo xx: El rol de la organización gremial de los arquitectos (1907-1942) y el papel de las revistas de arquitectura (19131941). Tesis doctoral. Madrid: Universidad Politécnica de Madrid, Escuela Técnica Superior de Arquitectura de Madrid, 2004.

Juan Carlos Cancino. Fundición Paipote 1952. Territorio, asentamiento y arquitectura en el período de la industrialización nacional. Tesis de Magíster en Arquitectura, Tutor: Eugenio Garcés Feliú. Santiago de Chile: Pontificia Universidad Católica de Chile, 2008.

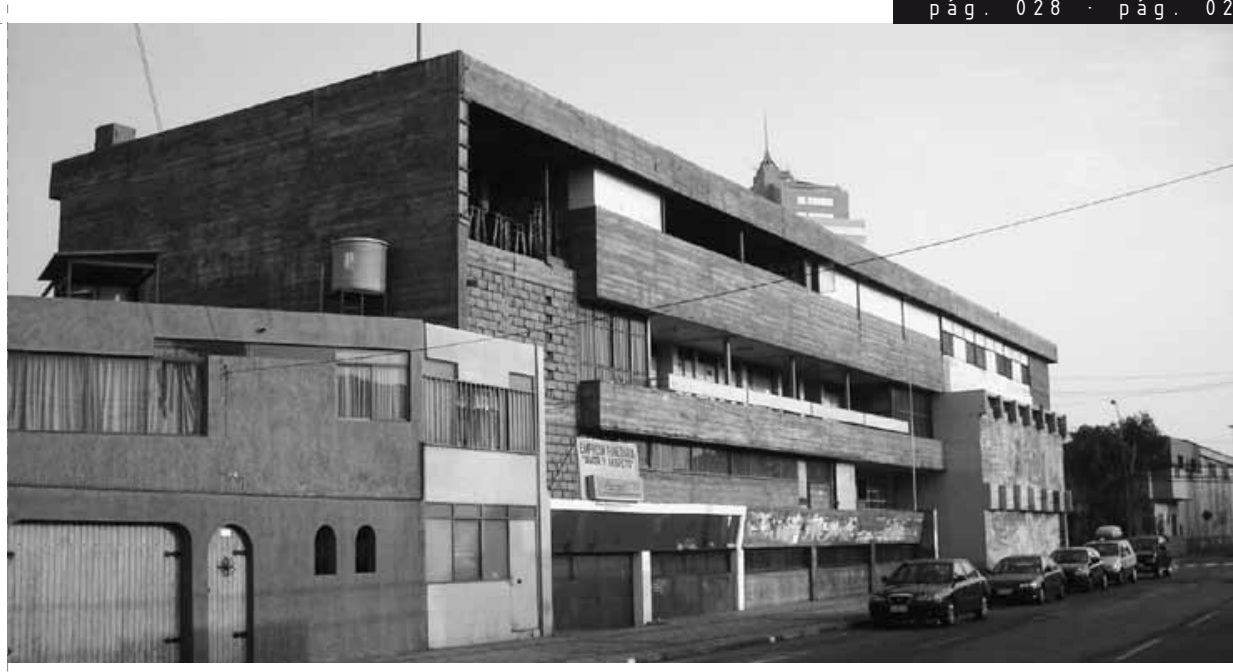

Sindicato de Estibadores Marítimos de Antofagasta, 1968-1971 arquitecto Alejandro Crestá Gouyou. ( C Claudio Galeno

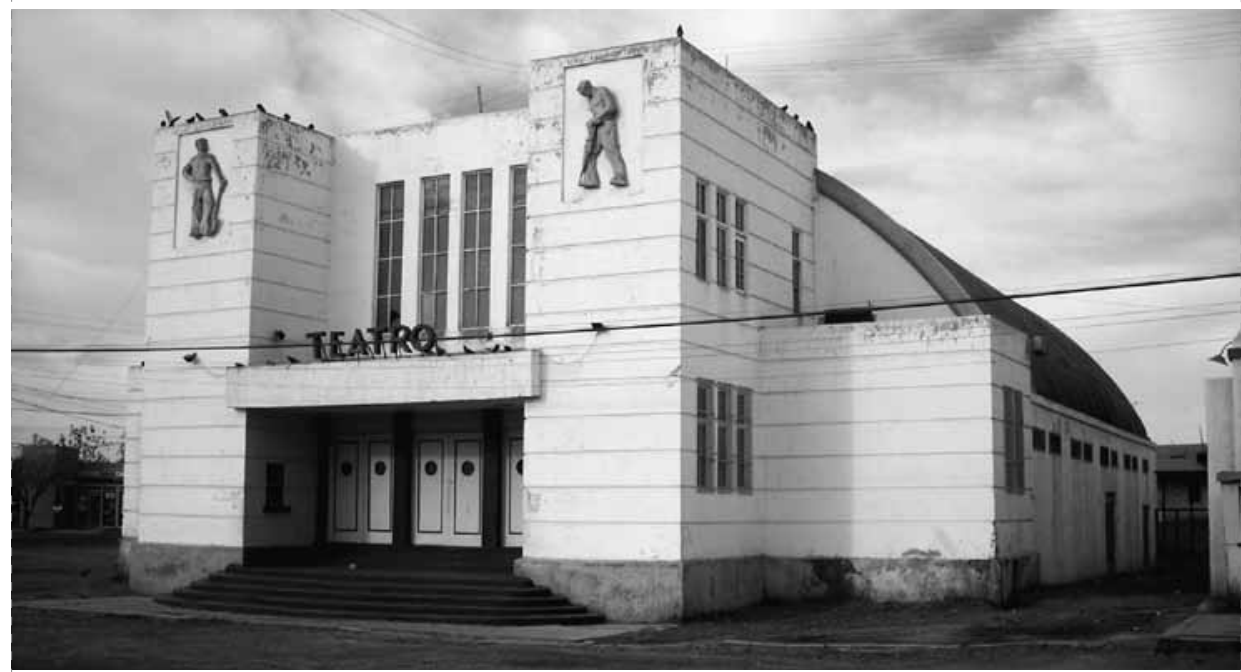

Teatro de María Elena, inaugurado en 1948, arquitecto no identificado. (C) Archivo Claudio Galeno.

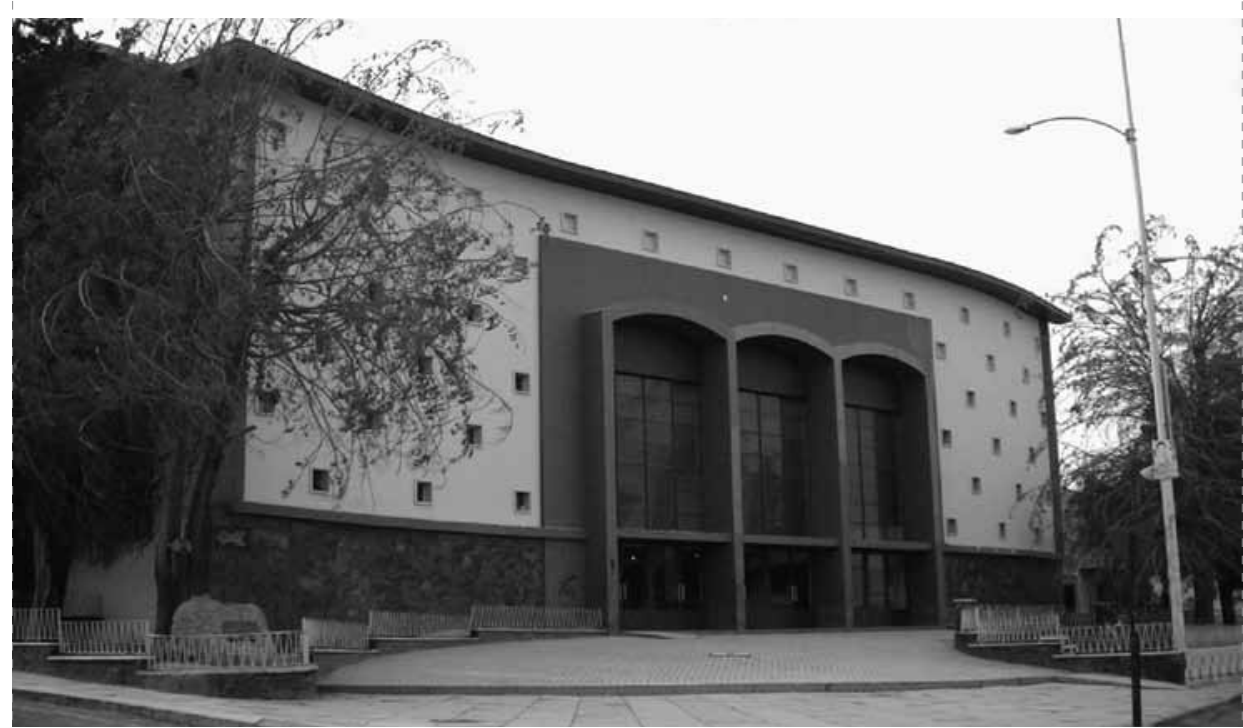

Auditorio-Teatro del Sindicato de Chuquicamata, arquitectos Alejandro Crestá Gouyou y Luis Lira, de 1959-61. O Archivo Claudio Galeno. 
Luciano Kulczewski. Discurso del delegado chileno D. Luciano Kulczewski, Administrador de la Caja de Seguro Obrero Obligatorio, en el Primer Congreso de la Vivienda en Buenos Aires. Revista Acción Social 1939; 82.

Corporación de Fomento de la Producción-Chile. Plan para el norte. CORFO, 20 años de labor, 1939-1959. Santiago, Chile: CORFO, 1959; p. 118.

Bernardita Devilat. Notas para una visión patrimonial del Hospital San Juan de Dios. Punto de Inflexión de la Arquitectura Moderna en Chile. Desafíos del patrimonio moderno. $2^{\circ}$ Seminario Docomomo-Chile. Edición Especial Revista Cuadernos de Arquitectura. Antofagasta: Departamento de Arquitectura, Universidad Católica del Norte, 2007.

Humberto Eliash Díaz, Manuel Moreno Guerrero. Arquitectura y modernidad en Chile (19251965). Una realidad múltiple. Santiago, Chile: Ediciones Universidad Católica de Chile, 1989

Hugo Ercilla Olea. Arica, un centro de atracción internacional. Revista En Viaje 1964; 374; p. 15.

Claudio Galeno. La arquitectura progresista de Antofagasta. Conciencia moderna o amnesia contemporánea. Actas del Primer Seminario Docomomo-Chile. Santiago de Chile: Docomomo-Chile, 2005; pp. 30-36.

Claudio Galeno. Concepción sanitaria de la arquitectura: La salubridad que marcó el espacio moderno. Revista Ciudad y Arquitectura (CA), Ciudad v/s Salud 2006; 125: pp. 36-37.
Claudio Galeno. Edificios colectivos para obreros La Caja de Seguro Obrero Obligatorio y la arquitectura social de Luciano Kulczewski en Antofagasta, Chile. Revista Cuadernos de Arquitectura, Habitar el Norte 2006; 10: pp. 23-28.

Claudio Galeno Ibaceta. Antofagasta, Chile. Modern architecture between ocean and desert. Docomomo Journal 2007; 37; pp. 24-29.

Claudio Galeno I. Destinos y pertenencia: Arquitecturas para el turismo moderno en el norte de Chile. En: Resúmenes de Ponencias, SAL XII, Seminario de Arquitectura Latinoamericana, Pensamiento construido: La investigación en arquitectura y urbanismo en Latinoamérica. Concepción: Facultad de Arquitectura, Construcción y Diseño, Universidad del Bío-Bío, 10-17 de noviembre de 2007, p. 104

Guía del Veraneante. Publicación Anual de Turismo Editada por la Sección Propaganda y Turismo de la Empresa de los Ferrocarriles del Estado. Santiago, Chile: Talleres Gráficos de los Ferrocarriles del Estado, 1953, 1956, 1960, 1961, 1962

Guía Turística: Chile 1968, 1972. Publicación Anual de Turismo de la Empresa de Ferrocarriles del Estado. Sección Propaganda y Turismo. Santiago, Chile: Talleres Gráficos de los Ferrocarriles del Estado, 1967.

Alfonso Jeria, Juan Hormazábal G. Conozca el Norte de Chile. Chile: Imprenta Libertad, 1954.
Alfredo Jünemann. Arquitectura del inicio del modernismo. Oficinas G. Mönckeberg y J. Aracena y la arquitectura educacional 1920-1950 Chile, Proyecto DIPUC 99/09C, Pontificia Universidad Católica de Chile, 2000.

Alberto Montealegre Klenner. Emilio Duhart arquitecto. Santiago, Chile: Ediciones $A R Q$, 1994.

Fernando Pérez Oyarzún. Bresciani Valdés Castillo Huidobro. Santiago de Chile: Ediciones ARQ, 2006.

Giovanna Rossi Bizjak. Tocopilla: Reseña histórica y desarrollo urbano. Tocopilla: Norgener SA 1993.

Sociedad Constructora de Establecimientos Educacionales (Chile). 25 años: 29 de noviembre de 1937/ Sociedad Constructora de Establecimientos Educacionales. Santiago: Zig-Zag, 1963.

VVAA. Arica en el tiempo. Reseña fotográfica, Universidad de Chile - Sede Arica, 1980.

VVAA. Seminario de Problemas Regionales de Antofagasta (1956). Santiago de Chile: Ediciones del Departamento de Extensión Cultural de la Universidad de Chile, 1957

VVAA. Seminario de Problemas Regionales de Atacama (1956). Santiago de Chile: Departamento de Extensión Cultural, Universidad de Chile, 1957. 